1978

\title{
Direct Determination of Pentachlorophenol by Differential Pulse Polarography
}

Albert L. Wade

Virginia Commonwealth University

Follow this and additional works at: https://scholarscompass.vcu.edu/etd

Part of the Chemistry Commons

() The Author

\section{Downloaded from}

https://scholarscompass.vcu.edu/etd/3936

This Thesis is brought to you for free and open access by the Graduate School at VCU Scholars Compass. It has been accepted for inclusion in Theses and Dissertations by an authorized administrator of VCU Scholars Compass.

For more information, please contact libcompass@vcu.edu. 
DIRECT DETERMINATION OF PENTACHLOROPHENOL BY DIFFERENTIAL PULSE POLAROGRAPHY

A thesis submitted in partial fulfillment of the requirement for the degree of Master of Science at Virginia Commonwealth University

\author{
by \\ Albert L. Wade \\ Director: Dr. Fred M. Hawkridge \\ Assistant Professor of Chemistry \\ Virginia Commonwealth University \\ Richmond, Virginia \\ May, 1978
}




\section{ACKNOWLEDGMENTS}

The author thanks Dr. Fred M. Hawkridge for providing the research problem, and for his inspiration, guidance and patience during the work on my research project. In addition, the author thanks Thomas Salmon for preparing the electrolysis cell materials, and for his helpful advice during work on the research project.

The author recognizes the contributions of Robert W. Phillips, William Z. Hudson and William M. Bowser of the American Tobacco Department of Research and Development for providing mass spectrometric, gas chromatographic and infrared spectrophotometric microsampling analyses of pentachlorophenol and electrolyzed pentachlorophenol during this research project.

The author also appreciates the assistance from Mrs. Dorothy Robben and her library staff of the American Tobacco Department of Research and Development for their assistance in obtaining reprints of articles needed in this research.

In addition, the author recognizes the contribution of his wife, Nancy, to the medical background on $P C P$, and thanks her for patience and understanding during work on this thesis. The author also thanks his daughter, Melanie, for her sacrifice during this time. 


\section{TABLE OF CONTENTS}

chapter

page

LIST OF TABLES.

v

LIST OF FIGURES.

vi

LIST OF ABBREVIATIONS................

vii

ABSTRACT.

viii

I INTRODUCTION.

Uses of Pentachlorophenol...........

Toxicity of Pentachlorophenol........

5

Physiological Effects of Pentachlorophenol.................

Safety Guidelines for Pentachlorophenol Exposure..............

Examples of Pentachlorophenol

Poisoning.................

Properties of Pentachlorophenol......

II A REVIEW OF METHODS FOR PENTACHLOROPHENOL.

Spot and Colorimetric Tests.........

Paper and Thin-Layer Chromatography..

Spectrophotometric Methods..........

Acid-Base Titration, Liquid-Liquid

Extraction....................

Gas Chromatography................

Miscellaneous Other Techniques for

Pentachlorophenol. 
chapter

page

III ELECTROCHEMICAL TECHNIQUES USED IN DEVELOPING A DIRECT METHOD FOR PENTACHLOROPHENOL.

40

Differential Pulse Polarography.... 41

Differential Pulse Voltammetry..... 49

Cyclic Voltammetry at the Hanging

Mercury Drop Electrode............

IV EXPERIMENTAL.....................

Instrumentation................ 57

Other Equipment................ 60

Reagents...................... 61

Electrochemical Procedures.......... 64

Paper and TLC Procedures........... 69

V RESULTS AND DISCUSSION............... 73

The Differential Pulse Polarography Investigation of Pentachlorophenol with the Dropping Mercury Electrode

The Differential Pulse Voltametry Investigation of Pentachlorophenol with the Carbon Paste Electrode....

The Cyclic Voltammetry Investigation of Pentachlorophenol with the Hanging Mercury Drop Electrode.....

The DC Polarography Investigation of Pentachlorophenol.............

Investigation of Reduction Products of Pentachlorophenol............. 
IIST OF TABLES

Table

page

1. Physical Properties of Pentachlorophenol....

2. Solubility for Pentachlorophenol...........

20

3. Data from the Mass Spectrum of Pentachlorophenol.............................

62

4. Data from the Study of Pentachlorophenol at the Dropping Mercury Electrode in 0.01 Molar Phosphate Buffer......................

5. Data from the Study of Pentachlorophenol at the Carbon Paste Electrode in 0.1 Molar

Phosphate Buffer at pH $8 \ldots \ldots \ldots \ldots \ldots \ldots \ldots \ldots$. 
LIST OF FIGURES

Figure

page

1. (a) Pentachlorophenol and (b) Sodium pentachlorophenoxide.

2. Sequence of events occurring during two mercury drops in DPP. (A) Voltage pulse applied to the dc ramp. (B) Charging and faradaic pulse currents. (C) Faradaic pulse current.........................

3. Triangular wave-form applied to HMDE and the general shape of the cyclic voltammogram............................

4. Differential pulse polarograms of PCP at the DME in $0.01 \mathrm{M}$ phosphate buffer, $\mathrm{pH} 9.0$ (a) $102 \mu \mathrm{M}$ (b) $8 \mu \mathrm{M}$ (c) $6 \mu \mathrm{M}$ (d) $42 \mu \mathrm{M} \ldots . . .$.

5. The effects of $\mathrm{pH}$ on differential pulse polarograms of PCP in $0.01 \mathrm{M}$ phosphate buffer at the DME.

6. Differential Pulse Polarograms of PCP at the CPE in $0.1 \mathrm{M}$ phosphate buffer, $\mathrm{pH} 8.0$ (a) $5 \mu \mathrm{M}$ (b) $4 \mu \mathrm{M}$ (c) $2 \mu \mathrm{M}$ (d) 1 uM.

7. Current-concentration relationship for PCP at the $\mathrm{CPE}$ in $0.1 \mathrm{M}$ phosphate buffer, $\mathrm{pH} 8.0 \ldots \ldots \ldots \ldots \ldots \ldots \ldots \ldots \ldots \ldots \ldots \ldots \ldots . \ldots \ldots$

8. Cyclic voltammogram of $0.5 \mathrm{mM} P C P$ in 0.01 $M$ phosphate buffer, $\mathrm{pH}$ 10.0. Scan rate 0.2 volts/second....................... 


\title{
IIST OF ABBREVIATIONS
}

\author{
CPE carbon paste electrode \\ CV cyclic voltammetry \\ DPP differential pulse polarography \\ DPV differential pulse voltametry \\ DC direct current \\ DME dropping mercury electrode \\ HMDE hanging mercury drop electrode \\ PCP pentachlorophenol \\ $R_{f} \quad$ ratio of sample spot to the solvent front. \\ TLC thin-layer chromatography
}




\section{ABSTRACT}

Concern over environmental contamination leading to the introduction of pentachlorophenol into human and animal systems has resulted in the need for a rapid and direct method for determining trace concentrations of this highly toxic compound. A direct electrochemical procedure has been developed for determining trace conccentrations of this phenol down to $0.27 \mathrm{ppm}$. This method uses the electrochemical techniques of differential pulse polarography at the dropping mercury electrode, and differential pulse voltammetry at the carbon paste electrode to reduce pentachlorophenol for this determination.

Cyclic voltammetry at the hanging mercury drop electrode has been used to characterize the reaction behavior of pentachlorophenol. Two voltametric peaks were found with this procedure. A voltammetric peak at -0.4 volts versus $\mathrm{Ag} / \mathrm{AgCl}$ exhibited the adsorption-desorption characteristics of a non-faradaic reaction by its shape and behavior at different scan rates. A reduction peak at -0.8 volts coupled with its oxidation peak exhibited the behavior for a faradaic electron-transfer reaction, and this peak was used in developing the method for 
pentachlorophenol.

Controlled potential coulometry was used to electrolyze a bulk concentration of pentachlorophenol at -1.1 volts versus $\mathrm{Ag} / \mathrm{AgCl}$ in an attempt to obtain enough reduced material to identify the reduction products. This electrolyzed material was investigated with gas chromatography, infrared and UV spectrophotometry, and paper and thin-layer chromatography for this purpose. No reduction products of pentachlorophenol were found with any of these techniques. The surface of the mercury pool, which was used as the working electrode in the coulometric cell, may have been passivated during electrolysis, which prevented significant reduction of pentachlorophenol.

The electrochemical procedure that was developed for pentachlorophenol analysis from my research offers some advantages of being fast and direct compared to the methods that are currently available for this purpose. 
CHAPTER I

INTRODUCTION

Concern over environmental contamination leading to the introduction of highly toxic pentachlorophenol (PCP) into human and animal systems has resulted in the need for a rapid and direct method of analysis. In my research, I have sought to develop an electrochemical method for determining trace concentrations of PCP using differential pulse polarography at the dropping mercury electrode, and differential pulse voltammetry at the solid state carbon paste electrode.

Analytical methods currently available for analyzing PCP utilize spectrophotometry, paper and thin-layer chromatography, gas chromatography with an electroncapture detector and mass spectrometry for identifying and measuring trace concentrations of the compound. In this study, a new assay procedure for PCP is described, that is based on its electrochemical reduction at either the dropping mercury electrode or the carbon paste electrode. This behavior is unique for PCP, since phenolic-type compounds are typically oxidized in an electrochemical sys- 
tem (1).

Although the method described in this thesis is not as sensitive as the more complicated gas chromatographic methods, the results obtained in our study indicate that it can be used to screen for PCP contamination in the environment.

\section{Uses of Pentachlorophenol}

PCP and its sodium salt have been used extensively by industry and individuals as pesticide, molluscicide, fungicide, bactericide, herbicide and defoliant. Bevenue and Beckman (2), among others, have described an impressive array of uses for this compound.

Because of its universal toxicity to insects, PCP has become one of the leading nonspecific pesticides used in our environment. It has been added to fabrics for mothproofing (2). PCP has found unprecedented application in the construction and lumber business for protection against termite infestation, for powder post beetle destruction, and for protection against any other type of insects that attack wood $(3-5)$. Bevenue (2) has reviewed its uses around home foundations, in wooden agricultural building materials, in all types of wooden posts and in wooden crate material used in packaging and shipping raw 
agricultural products.

One very important application of PCP is in the control of snails, which act as intermediate hosts for the larvae that cause schistosomiasis in man. Haskins (6) and Weinbach (7) have discussed its use for this purpose. Schistosomiasis is a blood-fluke disease, in which the male and female adult worms live in the veins of their victims (8). The snails perpetuating this life-cycle are found in streams, irrigation ditches, swamps, lakes, and contaminated drinking water supplies in areas, where schistosomiasis is prevalent.

Many applications have been found for PCP as a fungicide and bactericide. According to Erne (9) and Bevenue (2), it has been used as a soil disinfectant, especially around homes to control mold. Wallin (10) discussed its use in solutions for mildew-proofing, and according to Bevenue (2), PCP has been extensively used in paints, rug shampoos and textiles to control mildew. Van Langeveld (II) discussed its use in toy paint, water color, showcard paints and colored inks, and developed a gas chromatographic method for measuring PCP concentrations in paints and colors used by children. This compound has also been used to control fungus and bacteria growth in the processing of cellulosic products, starches, adhesives, proteins, leathers, oils and all types of foods (2). Indeed, one Japanese manufacturer of soy sauce added PCP 
directly to his product as a preservative until the Japanese Health Authorities discovered its illegal use (12). This compound has also been used in the manufacture of closure-sealing gaskets for food containers (2). Another use found for PCP is as a preservative against bacterial attack on natural rubber latex (13). It is also used in the control of fungus diseases on a variety of food crops. Cheng and Kilgore (14) described its use as a fungicide on almonds, cherries, peaches, prunes, apricots and apples. They developed a gas chromatographic method for determining PCP residues on fruits. Gordon (15) discussed the use of PCP to preserve hemp, jute, gums, glues and industrial proteins against molding. The Monsanto Corporation (16) cites a very important use of PCP in the cooling towers of electric power stations, petroleum refineries, air conditioning installations and various other processing industries for the prevention of bacteria, slime and algae growth. In another report, Armstrong et al. (17) discussed the use of an antimicrobial laundry neutralizer containing sodium pentachlorophenoxide in a hospital laundry as a general-use disinfectant.

Agriculture has made extensive use of PCP as a herbicide and defoliant. Bevenue (2) has discussed several applications of the compound for controlling weeds on pasture land, and in pineapple and sugarcane fields. 
Cheng and Kilgore (14) mentioned its use as a preplanting herbicide. Yip (18) discussed the application of PCP as a preplanting herbicide and preharvest defoliant on crops producing cooking oils. He developed a gas chromatographic method to determine PCP contamination in cottonseed, corn, safflower, soybean, peanut and olive oils produced from these crops. Ide et al. (19) studied breakdown products formed from the application of PCP to rice paddys as a herbicide. The Russians have used a formulation containing PCP as a dessicant for radish, carrot, beet, lettuce and onion seed crops. Lipinski et al. (20) claim that crops treated with this dessicant were ready for harvesting within six-to-fifteen days after application, resulting in increased seed jield and a higher germination rate. All of these uses for PCP are intended to indicate the extent of its proliferation in, and contamination of the environment. This is not a complete list of uses for the compound.

Toxicity of Pentachlorophenol

PCP is a well-known bactericide, molluscicide and pesticide, because of its toxicity to these forms of life, but its toxicity is not limited to such organisms. Many harmful effects from PCP contamination have been re- 
ported in fish, birds, domestic animals and man. Several studies have been made on the toxic nature of its biological activities in living organisms. Some of these studies have examined the physiological effects of PCP on these organisms, while others have attempted to establish safety guidelines for exposure of the organisms to PCP. Examples of illnesses and deaths from PCP poisoning have been discussed in some of these reports.

\section{Physiological Effects of Pentachlorophenol}

PCP has been found to interfere with metabolism in snails and rats. In his study on the physiological properties of PCP, Weinbach (7) found that the compound produced elevations of pyruvate, acetate, lactate and phosphate levels in snails. He reasoned that the acetate and lactate were the normal end-products of fermentative metabolism, but that the pyruvate and phosphate could have been produced from an altered aerobic metabolic process. He observed that the PCP only increased the rate of fermentative metabolism. This unexpected metabolic behavior led Weinbach to investigate the effects of PCP on the formation of energy-rich phosphate compounds in the presence of carbohydrates. He found that PCP blocked the formation of the adenosine triphosphate (ATP), which is normally pro- 
duced by this aerobic phosphorylation process. In effect, PCP disrupts the energy-yielding mechanism of the aerobic organism. Weinbach also reasoned that PCP might accelerate the breakdown of ATP in the living organism. In his study of rat liver mitochondria containing added ATP, he found that PCP increased the phosphate content of the cell at the expense of the ATP. As a result, he concluded that PCP not only inhibits the oxidative phosphorylation process but dissociates oxidative phosphorylation. In other observations from this study, Weinbach noted that PCP caused an increase in respiration and a rapid swelling, with subsequent rupture of the mitochondrial walls in snails and rats. Ultimately, these morphological changes from PCP poisoning prove fatal to the aerobic organism.

In a later study, Parker (2l) investigated the action of PCP on the enzymic activity in rat liver mitochondria. He found that PCP produced a maximum stimulation of ATP-ase activity at the same concentration that it produced maximum glutamic acid oxidation. The data gathered from this study also demonstrated that PCP inhibits oxidative phosphorylation that is normally associated with the oxidation of glutamic acid by $50 \%$ at $9 \times 10^{-6}$ molar and higher concentrations. Parker found that this behavior of PCP parallels that of 2,4-dinitrophenol, which is routinely used by scientists in studies 
on plant and animal metabolism to inhibit oxidative phosphorylation.

In another research investigation, Weinbach and Garbus (22) identified the actual binding site of PCP in the mitochondria as the protein component. These workers used a spectrophotometric method to discover the binding characteristics of the mitochondrial components after their exposure to PCP. Surprisingly, they found that the insoluble protein residue remaining after extraction of the lipids and water-soluble components of the mitochondria, bound PCP at equivalent or greater concentrations than the unextracted mitochondrial material, even with changes in $\mathrm{pH}$, phenol concentrations, or protein content. Thus, the insoluble protein attracts and concentrates the PCP in the mitochondrial cell. These authors also discovered that this protein-PCP bond was not affected by repeated washings with $0.25 \mathrm{M}$ sucrose solution, but that all of the PCP was removed from the protein in a single washing with bovine serum albumin. This reversible behavior indicated that they were dealing with an anion-anion type of protein-PCP bonding, rather than a covalent linkage. This anion-anion type of bonding with PCP would be expected to alter the normal ionic atmosphere of the mitochondria. For example, there would be changes in the types and amount of materials moving across the mitochondrial membrane in 
both directions, Weinbach (7) reported that PCP produces a loss of normal cell components, such as mitochondrial nucleotides and other nitrogenous material. The author also found that large concentrations of PCP produced rapid swelling and subsequent rupture of the mitochondrial membrane.

Smejtek et al. (23) produced evidence that toxic concentrations of PCP increased the electrical conductivity across lipid bilayer membranes of exposed organisms. The magnitude of the increased conductance is dependent on the $\mathrm{pH}$-types of lipids involved and the cholesterol content of the membrane. Their experimental results indicated that the membrane-permeable species causing this change in conductivity is a dimer formed from a neutral and a dissociated PCP molecule in the membrane surface. The PCP anion dimer produces a more negative potential at the membrane surface, which enhances the membrane conductivity to negatively charged species. These changes affect the basal metabolism rate of the organism.

PCP has also been found to interfere with nerve impulses. Saarikoski and Kaila (24) investigated the action of PCP on the abdominal tonic motor system of crawfish in an attempt to define the effects of PCP on the nervous system. This motor system controls all of the postural and slow movements of the abdomen in the craw- 
fish. The authors found that PCP produced changes in the impulse frequencies of these axons in concentrations above one ppm. PCP inhibited the velocity of conduction in the smaller nerve fibers and excited the larger nerve fibers. These authors attribute these changes to PCPinduced depolarization of excitable cell membranes belonging to the tonic motor system. In effect, PCP interferes with nerve impulses moving along the axons, and this interference can prove fatal to the organism. One of the earliest symtomatic studies on PCP toxicity in living organisms was made by Kehoe et al. (25). These researchers used rabbits to investigate the toxic effects of PCP caused by its application to the skin, and subsequent absorption through the skin. They found that sublethal dosages of PCP increased the respiration and cardiac activity of their rabbits within an hour of application. Elevation of body temperature and blood sugar levels followed. An accelerated loss of body fluids containing glucose and lactose also occurred from diuresis and diarrhea. These animals also lost their appetites, which caused a subsequent loss of weight. The PCP damaged the skin of some rabbits at the application site. Lethal cutaneous applications of PCP intensified all of these symptoms, with onset of changes often occurring in twenty minutes of application to the skin. In addition, 
these rabbits rapidly lost muscular response, often developed respiratory convulsions, and died with a fever of 107 or $100^{\circ} \mathrm{F}$. Death occurred in all of these animals within 6.5 hours after treatment with PCP and its sodium salt. Autopsies on the animals revealed extensive damage to the heart, blood vessels, lungs, liver, kidneys and lower genito-urinary tract. The tissue from most of the organs generally showed signs of swelling, congestion and hemorrhaging.

Gordon (15) has described his clinical experience with the toxic effects of PCP and its sodium salt in several patients that used the compounds. He found symptoms of nausea, loss of appetite and mild abdominal pain in patients with mild cases of PCP poisoning. In more severe cases, he reported acute abdominal pain, nausea and vomiting, followed by profuse sweating and intense thirst. The body temperature was often elevated, with an extremely rapid pulse rate and increased respiration. Gordon investigated nine cases of PCP poisoning resulting in five deaths. Autopsies on the five fatalities showed some damage to internal organs that could have been caused by PCP.

In another report, Bergner et al. (26) reported the clinical symptoms in five patients poisoned by PCP, one of which died. In the four nonlethal cases, the 
patients developed clinical symptoms of sweating, weight loss and gastrointestinal disturbances. In the terminal case, Bergner et al. reported symptoms of profuse sweating, an elevated and fluctuating body temperature, an irregular heartbeat, and a semiconscious state. An autopsy on the deceased showed cardiac dilation, pulmonary congestion, liver damage and kidney damage.

Chapman and Robson (27) have written an excellent summary of the clinical symptoms caused by PCP poisoning. The early symptoms found by these physicians include sweating, weakness, loss of appetite and weight, headache, dizziness, nausea, vomiting and difficulty in breathing. Elevated temperatures to $108^{\circ} \mathrm{F}$. have been recorded in fatal cases. Rapid heartbeat, labored breathing and thoracic or abdominal pain are followed by dehydration, convulsions and coma. These workers indicated that most deaths from PCP poisoning occur within three to thirty hours after the appearance of the first symptoms.

Safety Guidelines for Pentachlorophenol Exposure

Several studies have been made on living organisms to define the maximum concentration of PCP that can be tolerated without harmful effects or death. Kehoe et al. (25) applied varying concentrations of PCP to the 
skins of rabbits in an attempt to determine the toxicity of this compound. The compound was lethal to the rabbits at concentrations of thirty-nine milligrams per killogram of animal weight in pine oil. The toxicity varied with the solvent. These workers also studied the effects of sodium pentachlorophenoxide in aqueous solution on rabbits. They found that the smallest lethal dose of the salt is $257 \mathrm{mg}$ per $\mathrm{kg}$ of body weight when applied to the skin, $218 \mathrm{mg}$ per $\mathrm{kg}$ when ingested by mouth and $22 \mathrm{mg}$ per $\mathrm{kg}$ when given intravenously. They were unable to find evidence for any long term accumulative effects of PCP in rabbits.

In a later study, McGavack et al. (28) experimented with dogs and rabbits to find the threshold limits of PCP that produced acute intoxication. Solutions of sodium pentachlorophenoxide in water were used in this study. The minimum lethal dose that could be applied to the skin of these animals was $512.5 \mathrm{mg}$, from subcutaneous application $275 \mathrm{mg}$, from interperitoneal application 135.5 $\mathrm{mg}$ and from oral application $550 \mathrm{mg}$ per $\mathrm{kg}$ of body weight. They found only a small difference between the minimum lethal dosage of PCP and the amount of PCP that caused death in a single treatment during an accumulative study on the compound. This finding indicated to them that no significant cumulative behavior exists, and suggests that the drug is either excreted or destroyed in the body bet- 
ween treatments in the long term study. These authors also investigated the chronic effects of PCP polsoning on the animals by administering $3 \mathrm{cc}$ doses of $0.5-10 \%$ solutions of the compound daily. They found that a $1 \%$ solution of PCP demaged the skin, caused cerebral changes, caused hemorrhaging in the central nervous system, produced possible thymic changes, interferred with metabolism and altered the blood chemistry.

Goodnight (29) investigated the toxicity of PCP to fish. He found that the compound kills the more sensitive species of $\mathrm{fish}$ in concentrations above $0.2 \mathrm{ppm}$, with the hardier species surviving at 0.4 to $0.6 \mathrm{ppm}$ PCP. The size of the fish, the water temperature and the $\mathrm{pH}$ of the water affected the toxicity of PCP to the fish.

Bevenue and Beckman(2) have made an extensive study of dosage levels and effects of PCP contamination on man. They have found that the compound is absorbed through the skin and by inhalation, with subsequent irritation to the skin, eyes, nose and throat. The critical dosage for producing illness in man is not known, but they found evidence that from 4 to $8 \mathrm{mg}$ of PCP per $100 \mathrm{ml}$ of blood will produce symptoms of PCP poisoning. In another study, the American Governmental Industrial Hygienists reported that the threshold limits for PCP in air is $0.5 \mathrm{mg}$ per cubic meter of air (30). 
Bevenue et al. (3I) studied the PCP concentration in the urine of 201 randomly selected people in Hawail who were exposed to the compound in their work. They found a mean concentration of $23 \mathrm{ppb} P C P$ in this group of people. In this same paper, the authors referred to another study in which from 10 to $50 \mathrm{ppb}$ PCP was found in the urine of 20 randomly selected people in Alaska. In a related study, Bevenue and his coworkers (32) found that a large group of people in the Hawailan population showed a reasonably well established mean of from 40 to $44 \mathrm{ppb}$ PCP in their urine. These workers have concluded from their studies that there is a low level exposure to PCP in the population, who are not using the material directly, and that less than $50 \mathrm{ppb}$ PCP would be expected in the urine of this general population.

Examples of Pentachlorophenol Poisoning

Vermeer and his coworkers (33) reported a large fish kill in Surinam in 1971, after the surrounding rice fields were sprayed with PCP to control snails. Following the application of PCP, many birds were found sick or dead from feeding on the fish that had been killed by the compound.

A large kill of carps was reported to have occurred in the ponds around a Japanese village in 1976 
after PCP had been used as a herbicide on near by rice fields (34).

Schipper et al. (35) reported an incident of $P C P$ poisoning in swine confined to a pen, where the floor slats had boen treated with PCP. All of the pigs in that pen developed acute toxicosis, listlessness and skin irritation. One severly burned pig died with internal lesions, that are characteristic of PCP poisoning.

Farrington and Munday (36) have reported evidence for the contamination of poultry flesh from PCP. Shavings from PCP-treated timber are routinely used as litter in some poultry broiler houses. As a result, these chickens absorbed the PCP into their bodies from daily contact with the material.

In 1956, Gordon (15) reported on nine cases of PCP poisoning in men using the compound in Auistralia. Five of these individuals died from exposure to the compound.

Bergner and his colleagues (26) reported on five cases in which industrial workers in wood-processing plants in Canada were poisoned from absorption of PCP through the skin. One of these workers died from PCP poisoning.

Chapman and Robson (27) reported on the poisoning of a three year old child from an insecticide mixture, which had contaminated the domestic water-supply in 
England. The child was poisoned from PCP absorption through the skin from bathwater. The bathwater came from a cold-water storage tank located on the roof of the house. The water in the teink had been contaminated with an insecticide mixture of PCP used for spraying the roof timbers. other members of the same family had mild symptoms attributed to PCP poisoning. The child recovered after removal from the source of the contamination.

In another case, Bevenue et al. (31) reported a case of $\mathrm{PCP}$ poisoning in an individual cleaning a paint brush with-a $0.4 \%$ solution of PCP. After ten minutes of contact with the PCP solution, this worker developed a reddening in the tissue of the hands with pain, and this pain persisted for two hours even with repeated washing. The PCP had been absorbed through the skin, and was excreted through the urine at elevated concentrations for approximately one month after exposure. The individual recovered without further complications.

$P C P$ poisoning was reported in a nursery for newborn infants by Robson and his colleagues in 1969 (37). Nine neonatal infants from the same hospital were poisoned by PCP absorption through the skin. Two babies died, and six other babies were saved only after exchange blood transfusions. At least eleven other children from the same hospital also showed some symptoms of PCP poisoning, and all of these cases occurred during a five-month period. 
Armstrong et al. (17) traced the cause of PCP poisoning to an antimicrobial laundry neutralizer containing PCP, which was used as an additive to the terminal rinse cycle in the laundering of diapers, infant undershirts, sheets blankets, mattress covers and other linens from the nursery. The PCP was identified through autopsy findings, and in samples of serum and urine taken from the poisoned infants.

Polaskova et al. (38) reported a lethal case of PCP intoxication in a 29-year-old man in Czechoslovakia. The PCP was identified from autopsy samples by chromatographic methods.

\section{Properties of Pentachlorophenol}

An extensive review on the properties of PCP and its sodium salt was made in 1938 by Carswell and Nason (39), and in 1967 by Bevenue and Beckman (2). PCP (a) and sodium pentachlorophenoxide (b) have the structural formulas that are shown in Figure 1.

There are several names used for these compounds, depending on which manufacturer's brand is selected. It is variously called pentachlorophenol, PCP Chlorophen, Penta, Penchlorol, Sodium Pentachlorophenoxide, Dowicide G, Dowicide 7, Santobrite, Santophen 20, Pentacon, 
Penwar or Weedone (40). This compound may also be purchased in mixtures with other chemicals.

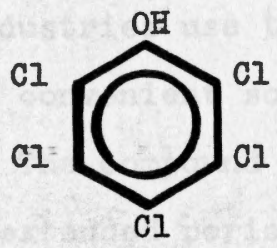

(a)

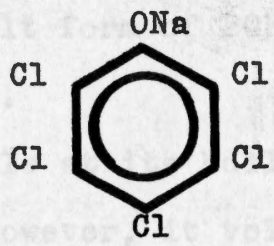

(b)

Figure 1: (a) Pentachlorophenol and (b) Sodium pentachlorophenoxide.

PCP is a white solid of needle-like crystals in the pure form. Some of the physical properties of PCP, that have been compiled by Bevenue et al. (2) are included in Table 1 .

\section{TABLE I}

Physical Properties of Pentachlorophenol

Molecular weight

Melting point

Boiling point

Density

$$
\begin{array}{r}
266.36 \\
190^{\circ} \mathrm{C} \\
293^{\circ} \mathrm{C} \\
1.85
\end{array}
$$

Vapor pressure $\left(20^{\circ}\right.$ to $100^{\circ} \mathrm{C}$ ) 0.00011 to $0.12 \mathrm{~mm} \mathrm{Hg}$ Solubility in water $\left(20^{\circ}\right.$ to $30^{\circ} \mathrm{C}$.) 14 to $19 \mathrm{ppm}$ 
The data in Table 1 shows that PCP has a very low solubility in water. At $\mathrm{pH} 8$, the solubility is increased to more than $4000 \mathrm{ppm}$ with the formation of its salt. Most industries use the sodium salt form of PCP because of this convenient solubility (2).

The compound is very stable at its boiling point for an extended period of time; however, it volatilizes with steam in acidic solutions $(2,39)$. At $100^{\circ} \mathrm{C}$ and standard atmospheric pressure, $0.167 \mathrm{~g}$ PCP are volatilized with each $100 \mathrm{~g}$ of steam. Decomposition products are produced from PCP and its sodium salt at $300^{\circ} \mathrm{C}$.

The solubility of PCP in most organic solvents, oils and petroleum hydrocarbons increases with increasing aromaticity and olefinic content. Bevenue et al. (2) have tabulated its solubility in some of the common solvents used in its analysis. Solubility data on PCP is listed in Table 2.

\section{TABLE 2}

Solubility for Pentachlorophenol

Methanol

Diethyl ether

Ethanol

Acetone

Benzene

Carbon tetrachloride
57 to $65 \mathrm{ppm}$

53 to $60 \mathrm{ppm}$

47 to $52 \mathrm{ppm}$

21 to $33 \mathrm{ppm}$

11 to $14 \mathrm{ppm}$

2 to $3 \mathrm{ppm}$ 
PCP is a highly stable compound in the pure form, but decomposition occurs in the environment under certain conditions. Stehl et al. (43) discovered that the phenol and its salts undergo rapid decomposition under ultraviolet light. These workers studied the nature of this decomposition under different sources of artificial and natural Iight.

Microorganisms in the soll have also been found to decompose PCP. Ide et al. (19) produced evidence that reductive dechlorination of PCP is produced by microorganisms in the soiz of rice fields in Japan. They followed this PCP decomposition for several weeks under controlled laboratory conditions. No PCP reduction occurred in sterilized soil from the same rice fields. The researchers isolated and identified the decomposition products by gas chromatography followed by mass spectrometry. They found that the ortho and para chlorines of the phenol undergo reductive dechlorination preferentially to the meta isomer. In another study, Suzuki ( 44 ) investigated the metabolism of $c^{14}$-tagged PCP by the Pseudomonas microbe, that is commonly found in soil. He found rapid assimilation of the tagged $\mathrm{c}^{14}$ atom into the cell constituents of the microbe. PCP is a weak acid with a $\mathrm{pK}_{\mathrm{a}}$ of 4.8 . This value was obtained by Smejtek et al. (23) using UV spectrophotometry. In their method, the authors plotted the absorbances 
of ionized PCP at $320 \mathrm{~nm}$ as a function of $\mathrm{pH}$, and selected the inflection point of the $\mathrm{r}_{1}$ sulting curve as the $\mathrm{pK}$ for PCP. Blackman et al. (45) obtained a similiar value from curves of optical density as a function of $\mathrm{pH}$. On the other hand, Nose and Fukunaga (46) calculated a $\mathrm{pK}_{a}$ of 4.49 from the absorbances of the ionized PCP at $321 \mathrm{~nm}$ and the neutral molecule at $304 \mathrm{~nm}$. Smejtek et al. considered the absorbance ratio of $1 / 70$ for the neutral-toionized PCP species at $321 \mathrm{~nm}$ to be insignificant in their calculations. Beilstein (47) reported a $\mathrm{pK}_{a}$ of 5.26 for PCP from a much earlier determination.

The absorptivities of PCP in ethanol and aqueous alkaline solutions have been determined $(2,9)$. Bevenue and Beckman (2) reported a molar absorptivity of 2930 for PCP in ethanol at $304 \mathrm{~nm}$. They also submitted values for the two UV peaks from PCP in aqueous alkaline solution. Molar absorptivities of 10,707 and 5087 were obtained at $248 \mathrm{~nm}$ and $320 \mathrm{~nm}$ respectively. Erne (9) found a molar absorptivity of 5100 for the latter peak in aqueous alkaline solution. Absorptivity values are reported in my thesis as molar absorptivities. 


\section{CHAPTER II}

A REVIEW OF METHODS FOR PENTACHLOROPHENOL

PCP generally contaminates the environment in trace amounts, because of its limited solubility in water and the small concentrations needed for effective pest controls. As a result, methods are required that are sensitive enough to detect and quantify microgram quantities or less of the compound. These methods must discriminate between PCP and other contaminants in the medium, effectively. In addition, they should be rapid, preferrably direct and not too complex. Many methods have been developed for PCP using spot and colorimetric tests, paper and thin-layer chromatography, spectrophotometry, acid-base titrations, liquid-liquid extraction, gas chromatography and miscellaneous other techniques. Some of these methods will be examined in the remainder of this chapter.

Spot and Colorimetric Tests

Several colorimetric procedures for PCP were developed before the advent of more sophisticated instrumental 
methods. Steigmann (48) reacted PCP with alkaline $\mathrm{AgNO}_{3}$ to develop a yellow spot test for the compound with a sensitivity of $10 \mathrm{\mu g}$ per sample. In this test, the silver pentachlorophenoxide salt is formed, which is insoluble in dilute acetic acid.

Deichmann and Schafer (49) developed a reddishyellow product from the reaction of fuming nitric acid with PCP, and measured the concentration-dependence spectrophotometrically at $460 \mathrm{~nm}$. Fuming nitric acid oxidizes PCP to a mixture of ortho and para tetrachloroquinones. The colored product was extracted into chloroform prior to spectrophotometric analysis of PCP from biological materials and water samples. These analysts established linear calibration curves from between $50 \mu g$ and one $\mathrm{mg}$ of PCP in water. Bevenue and Beckman (2) indicate that the detection limit of this procedure is $10 \mathrm{\mu g}$ of PCP per sample. There are some contaminants that may interfere with this analysis.

Gottlieb and Marsh (50) reported a color test for $\mathrm{PCP}$, in which they condensed 4-aminoantipyrine with PCP in the presence of potassium ferricyanide and dilute sodfum carbonate to form a green dye. The chlorine para to the hydroxyl group of PCP is expelled during the reaction, with the subsequent condensation of the primary amino group of 4-aminoantipyrine at the para position. These 
workers established a concentration-dependent curve at $640 \mathrm{~nm}$ for this dye, which they used for the analysis of PCP content in fabrics. The analysts established a callbration curve for between $300 \mu g$ and one $\mathrm{mg}$ of PCP for the method. Bevenue et al. (2) indicate that the detection limit for this procedure is 0.5 ppm PCP per determination.

Wallin (10) treated sodium pentachlorophenoxide with copper sulfate to form the copper salt, which dissolves in acidic alcohol. Treatment of the colorless acidic alcoholic solution with potassium ferrocyanide produced a colored copper ferrocyanide solution, which followed Beer's Law. Bevenue et al. (2) have shown that the detection limit for this reaction is $5 \mathrm{mg}$ of PCP per sample solution. In addition, Wallin formed a methylene blue-sodium pentachlorophenoxide complex for determining PCP concentrations down to $5 \mathrm{ppm}$ per sample.

Haskins (6) used safranin-O (CI 841) to develop a quantitative colored complex with PCP. He extracted this colored complex into chloroform, and took spectrophotometric measurements at $525 \mathrm{~nm}$. According to Bevenue et al. (2), this method will detect a minimum concentration of $5 \mu g$ of PCP per determination. Haskins has indicated that this method can be used for determining between $I$ and 100 ppm PCP in an aqueous solution. 
All of these colorimetric methods use pre-treatment procedures to obtain the chromophores, and other contaminants may interfere with the PCP determination. Also, most of the methods are not sensitive enough to measure less than milligram concentrations of PCP with any degree of accuracy.

\section{Paper and Thin-Layer Chromatography}

Paper and thin-layer chromatography have been used for separating and identifying PCP. These two techniques are similar, although thin-layer methods are faster, the spots are more compact, better separation is usually obtained and tailing problems are minimized.

Mitchell (5I) developed an aqueous solvent system for separating PCP by ascending paper chromatography. He mixed refined soybean oll diluted with ethyl ether for the Immobile phase, and water with 2-methoxyethanol for the mobile phase, and combined the two phases to prepare his solvent system. The chromatogram was developed in this solvent system for 4.5 hours before removing, drying and spraying with silver nitrate solution to locate PCP. The chromatogram was exposed to UV light after spraying with $\mathrm{AgNO}_{3}$ to develop the PCP spot at an $\mathrm{R}_{\mathrm{f}}$ value of 0.89 . Vacek et al. (52) have described another paper chromatography system for separating and identifying PCP. 
In this system, the workers separated PCP from phenolics by pH-chromatography. They impregnated the chromatogram with 10\% olive oll in benzene and used Britton-Robinson Buffers of different $\mathrm{pH}$ as the mobile phase in this separation. An $R_{f}$ value of 0.30 was found for PCP in this type of solvent system above a pH of 9. The PCP was detected by spraying with 4-aminoantipyrine, Folin-Ciocalteau reagent and UV light exposure.

Erne (9) developed a useful paper chromatography system for separating and 1dentifying PCP. In this system, the paper was impregnated with a mixture of propylene glycol, methanol and formic acid (50:50:1). After drying at $60^{\circ} \mathrm{C}$, the PCP mixture was applied, and the chromatogram was developed in the upper layer of an iso-octaneformic acid-propylene glycol $(10: 1: 2)$ mixture. An $R_{f}$ of 0.4 was obtained in this solvent system with a copper reagent. Erne also investigated a system in which the paper was impregnated with propylene glycol and the chromatogram was developed in iso-octane acidified with formic acid. Erne successfully separated PCP in this system with $R_{f}$ values between 0.3 and 0.5 .

Using thin-layer chromatography, Suzuki and Kato (53) have reported the separation of PCP from other phenols of its homologous series by 2-dimensional chromatography on a thin-layer silica gel plate. They developed the first direction in chloroform and the second direction in benzene- 
ethyl acetate $(10: 1)$. Deters $(54)$ has given an $R_{f}$ value of 0.50 for PCP in chloroform on weakly acidified silica gel plates. Bevenue and Beckman (2) discussed a detection method for PCP in which the thin-layer chromatogram is sprayed with $1 \mathrm{~N} \mathrm{KOH}$, heated and treated with $\mathrm{AgNO}_{3}$ followed by UV light for developing the spot.

In another study, Petrowitz (55) separated PCP by thin-layer chromatography from other pesticides with $n$-hexane. An $R_{f}$ of 0.48 was obtained in 7 minutes in this solvent system.

Tadema and Batelaan (56) used thin-layer plates coated with a mixture of silica gel and amylopectin to investigate the behavior of PCP in three solvent systems. They found a $R_{f}$ of 0.23 for PCP in benzene-ethanol (95:5), and $R_{f}$ values of 0.09 in the $n$-hexane-ethanol $(95: 5)$ and diethyl ether-n-hexane ( $1: 1)$ sovent systems. PCP was detected using bromine-potassium iodide on the chromatogram. Zigler and Phillips (57) used two-directional thinlayer chromatography (TLC) to separate PCP from its homologues in raw and treated river water. They employed benzene in the first direction to remove interferring organic contaminants. In the second direction, these workers used $6 \mathrm{ml}$ of $\mathrm{I} \mathrm{N} \mathrm{NaOH}$ in $94 \mathrm{ml}$ of acetone to separate PCP from other phenols. The used $\mathrm{AgNO}_{3}$ with a sensitivity of 0.1 $\mu \mathrm{g}$ and 4-aminoantipyrine with a sensitivity of $0.5 \mu \mathrm{g}$ to locate these phenols. These analysts found a $R_{f}$ of 0.09 
for PCP in this solvent system.

In another study, Davies and Thuraisingham (13) estimated the PCP content of natural latex by TLC. They obtained good separations with a chloroform-acetic acid (100:1) solvent system, and developed their color with PCP using a copper sulfate-pyridine, reagent. PCP gives an intense brown spot on a light blue background with this reagent, and has a $R_{f}$ value of 0.50 in this solvent system.

Frei-Häusler et al. (58) formed the dansyl derivative of PCP by reaction with 1-dimethylaminonaphthalene-5-sulfonyl chloride, and evaluated this compound by TLC. This derivative is fluorigenic, and after development in a benzene-chloroform (1:1) solvent system, the workers sprayed the chromatogram with triethanolamine in isopropanol and measured the concentration of PCP with a flourescence spectrometer. PCP has a $R_{f}$ of 0.83 in this solvent system, and these authors report that they can detect sub-microgram quantities of chlorophenols by this method.

Henshaw et al. (5) developed TLC plates containing PCP in cyclohexane-acetone-liquid paraffin $(15: 3: 2)$ in the first direction and ethyl acetate-glacial acetic acid $(2: 1)$ in the second direction to obtain $R_{f}$ of 0.25 for PCP. They used this method to determine PCP in wood after treatment with the preservative. 


\section{Spectrophotometric Methods}

Several UV spectrophotometric methods have been developed for the quantitatative determination of PCP. Laclair (59) used an elaborate extraction procedure to separate PCP and tetrachlorophenol from the other contaminating components in technical grade PCP. The absorbances of the final extract at 255 and $285 \mathrm{~nm}$ were determined, and the concentrations of the two compounds calculated with an average error of less than $5 \%$.

Erne (9) developed a specific UV method for detecting and quantitating PCP in biological material. He extracted the PCP from biological material, isolated it from other impurities by paper chromatography, eluted the resulting pure compound from the paper, and determined its concentration by UV spectrophotometry. The absorbance values for PCP were determined at 248 and $320 \mathrm{~nm}$ from an aqueous alkaline solution. In addition, Erne developed a base-line technique for subtracting out the background absorption from the PCP peak. In this technique, three absorbance values are obtained; one at the absorption peak for PCP, and one from each side at the minima of the peak. As little as $5 \mu \mathrm{g}$ of PCP from a gram of biological material can be detected by this method.

Basch and Hirschman (60) developed an UV method for the determination of PCP in fabrics, in which the absorb- 
ance was measured at $214 \mathrm{~nm}$. They reported the recovery of $100 \%$ of the PCP that had been added by them to the fabrics.

A special UV method was described by Fountaine and his coworkers $(41,61)$ for measuring dangerous levels of PCP contamination in a stream leading from an industry using this compound. In general, the method consisted of extracting the PCP from water with a solvent, and reading the absorbance at $320 \mathrm{~nm}$ using an UV ratio spectrophotometer that was custom-designed with a copper hollow-cathode lamp for this procedure. The method has a detection limit of about $2 \mathrm{ppb}$ PCP with no interference from other phenols.

Acid-Base Titration, Liquid-Liquid Extraction

Teplyakova and Timbekov (62) developed an interesting method for titrating small quantities of PCP in commerical products and in the air. They reacted PCP with a chromic mixture to liberate chlorine, which reacted with $\mathrm{CdI}_{2}$ to release iodine, and the liberated iodine was titrated with $\mathrm{Na}_{2} \mathrm{~S}_{2} \mathrm{O}_{3}$. Most of the titration methods that are available are used to determine much larger quantities of PCP, than the ppm-levels contaminating the environment, and will not be discussed in this thesis.

Several liquid-liquid extraction procedures for PCP have been used in methods that have already been dis- 
cussed in this chapter. Extracts of materials and contaminated water samples containing PCP must be purified before most analyses. Laclair (59) extracted technical grade PCP with a $5 \%$ solution of tetrasodium pyrophosphate to remove PCP from weakly acidic phenolic compounds before an UV determination. Erne (9) extracted biological material with ether to remove PCP before determining its concentration by UV analysis. Fountaine et al. (41) made dirty water samples basic and extracted with chloroform to remove any organic impurities, especially oils. He acidified the aqueous layer and extracted into chloroform to remove the PCP, which was extracted into $\mathrm{NaOH}$ solution and determined by UV spectrophotometry. Winn (63) patented a process for removing PCP from contaminated water with a methylene chloride countercurrent extraction procedure.

\section{Gas Chromatography}

One of the earliest gas chromatography (GC) methods for PCP was developed in 1962 by Barry, Vasishth and Shelton (64). They used this method for investigating the chlorinated by-products in the manufacture of chlorinated phenols. The group successfully separated PCP from its homologues with a silicone high vacuum grease column at $200^{\circ} \mathrm{C}$, and used infrared spectroscopy to confirm their compounds. These analysts were able to detect a minimum of $0.5 \%$ PCP 
by this method.

Burke and Johnson (65) developed a micro-coulometric GC method for the rapid screening and analysis of PCP and other pesticide residues in fruits and vegetables. They made the separations on acid-washed chromosorb P columns coated with a silicone high vacuum grease at $220^{\circ} \mathrm{C}$. A combustion furnace and a micro-coulometric detection system sensitive only to halides were employed in this analysis. These workers calculated the halogen content in a compound from the concentration of silver ions produced in the coulometric titration of the compound. Aqueous extracts of fruits and vegetables had to be purified on Fluorisil columns before the GC analysis.

The major problems in these early GC methods were poor sample resolution and tailing with the chlorophenols. Kolloff et al. (66) successfully used carbowax $20 \mathrm{M}$ plus $2 \% \mathrm{H}_{3} \mathrm{PO}_{4}$ on Gas Chrom $\mathrm{P}$ at $200^{\circ} \mathrm{C}$ to overcome these problems and resolve a mixture of chlorophenols containing PCP on one column without tailing.

Kanazawa (67) formed the methyl ether of PCP by reaction with diazomethane, and separated it from the methyl ethers of other chlorophenols. The methyl ether peaks were sharper than those for the original compounds. This author used silicone high vacuum grease and sodium alkylbenzene sulfonate columns at 150 to $190^{\circ} \mathrm{C}$ to determine the PCP concentration in herbicide formulations and other 
commerical products.

Cheng and Kilgore (14) developed a sensitive procedure for the determination of $\mathrm{PCP}$ residues in fruits using GC with electron-capture (EC) detection. They formed the methyl ether of PCP and chromatographed the sample on an acid-washed chromosorb $W$ column treated with silicone oil at $180^{\circ} \mathrm{C}$. The limits for detection by this method was $0.01 \mathrm{ppm}$ PCP with from 76 to $90 \%$ recovery of the sample.

Yip (18) used programmed temperature GC for determining PCP in vegetable oils. The PCP was extracted from the oil with chloroform and esterified with diazomethane prior to the GC analysis. He used a microcoulometric halide detector and claimed a recovery for PCP at above $90 \%$ in the 0.02 to $0.08 \mathrm{ppm}$ range of concentration. Argauer (68) prepared the chloroacetate derivative of $0.01 \mathrm{ppm}$ or less chlorophenol compounds, and determined the concentration by EC-GC. Aqueous solutions of the phenol were treated with chloroacetic anhydride in benzene to form the derivative. The rapid derivatization process of microgram quantities of PCP and related phenols with minimum manipulation is the main innovation of this method.

Stark (69) extracted PCP from contaminated soil and fish flesh with $0.1 \mathrm{M} \mathrm{KOH}$ followed by toluene. He prepared 
the trimethylsilyl ether of PCP, and determined its concentration by EC-GC coupled with a mass spectrometer. This author claimed that he could detect a minimum of 0.5 ppb PCP in soil and fish flesh by this method. He reported a recovery of added PCP of from 80 to $100 \%$. GC with EC has become the method of choice for PCP analysis, because it is extremely sensitive. Bevenue et al. (70) used this method to analyze for picogram quantities of PCP in human urine and blood. Higginbotham et al. (71) extracted the PCP from fats, oils and fatty acids, and used EC-GC for the quantitative detection at the 0.5 ppm level. Barthel et al. (72) identified PCP by this method in the blood, urine, tissue and clothing of infants poisoned by the compound in a nursery in St. Louis in 1969. Cranmer and Freal (73) formed the alkyl ether of PCP from human urine, and determined the concentration by EC-GC. Kilgore and White (74) successfully separated mixtures of chlorinated fungicides containing PCP in an all-glass isothermal system by EC-GC. Yip (75) investigated PCP and other chlorophenoxy acid residues in milk, fresh fruits and vegetables, wheat and meat-tissue with EC-GC. Shafik (76) used EC-GC to investigate PCP in human adipose tissue, where it is collected and stored in the human body. He concluded from this study that humans are continuously exposed to low levels of PCP from the environment, from 
food supplies and from disinfectants.

Buhler and his coworkers (77) coupled their GC with a mass spectrometer to measure PCP contamination in sewage river waste and treated drinking water supplies from the Willamette River in Oregon. They discovered that municipal drinking water supplies processed from this river still contained $40 \%$ of the PCP that was originally in the raw river water.

Parr et al. (78) used EC-GC to determine PCP contamination in wood preservatives used in broiler house litter, and Gee et al. (79) investigated the resulting contamination to the broiler chickens raised on this litter with the same technique. In another study on PCP contamination in natural and waste water, Chau and Coburn (80) claimed that they could determine a minimum of 0.01 ppb PCP per liter of water using EC-GC.

Van Langeveld (1l) used GC with flame ionization detection to investigate PCP levels in various types of toy paints, watercolors, body colors, showcard paints, gouache paints and colored inks. He extracted PCP from these materials with acetone, concentrated the sample, and injected it directly into the GC containing an acidwashed 60-80 mesh chromosorb P column coated with $15 \%$ carbowax 20M. He claimed a minimum detection limit of 1 ppm PCP with recoveries of from 70 to $100 \%$ PCP, depending 
on the type of paint used.

Villanueva et al. (8I) used EC-GC anà GC- mass spectrometry (MS) to determine the extent of contamination in commerical PCP. They estimated the contaminant content with EC-GC and used GC-MS to confirm and identify the contaminants.

Chriswell et al. (82) used a combination GC-MS to identify PCP and other contaminating phenols in natural water and treated drinking water. Initially, they absorbed these phenols on a macroporous anion-exchange resin, eluted the sample with acetone, injected it directly onto the GC column. The GC was equipped with a dual flame ionization detector. Their method gave precision results in the ppb to ppm range for these phenols. Buser and Bosshardt (83), and Mieure et al. (84) developed methods using GC-MS to detect and identify contaminants in commercial grade PCP.

In other studies, Hoben et al. (85) studied the absorption of PCP by inhalation in rats. They used EC-GC to determine the resulting PCP content in the plasma, urine and tissue of the exposed rats. Farrington and Munday (36) prepared the 2,4-dinitrophenyl ether derivative of PCP and determined its concentration by EC-GC. The identity of this derivative was confirmed by MS. They applied this method to extracts from chicken flesh, and 
indicated that the method gave good reproducible recoveries of PCP from standard solutions.

Krijgsman and van de Kamp (86) used capillary GC with EC to study the acetylated derivative of PCP and other chlorophenols. The reported an 80-100\% recovery from the extraction and acetylation steps for the chlorophenols, with a detection limit for PCP acetate of $1 \mathrm{pg}$.

The vast majority of these GC methods used EC to detect PCP and its derivatives. All of the GC methods for PCP used by stahr (87) in his "ANALYTICAL TOXICOLOGY METHODS MANUAL" for the analysis of blood and urine samples also used EC detection, because of its high sensitivity for this compound and its derivatives.

Miscellaneous Other Techniques for Pentachlorophenol

Infrared (IR) and MS analyses are mainly used in the identification of PCP following its isolation with GC or ion-exchange chromatography. There have been a few instances in which IR has been used to determine PCP without this preliminary purification. Bevenue et al. (2) discussed the use of IR analysis as a quality control method during the manufacture of PCP from the chlorination of phenol. Generally, the IR spectrum of PCP will be distorted in the presence of other closely related phenolics; 
therefore, the sample should be purified and isolated from these interferring compounds before IR analysis. Dougherty and Piotrowska ( 88$)$ have developed a quantitative procedure for PCP using negative ion chemical ionization MS. They surveyed the food chain, water supplies and other suspicious environmental materials, and related the PCP contamination from these sources to its concentration in various body fluids. These analysts isolated the PCP by solvent extraction, evaporated the solvent and determined the sample concentration. The results suggest that most of the PCP contamination in man comes from starch and sugar products. These materials may have picked up this PCP contamination from their PCP-treated storage and shipping containers.

Mizunoya (89) converted PCP to chloranil by oxidation with $\mathrm{HNO}_{3}$, extracted it into ether and determined its concentration by polarography in 50\% alcohol solutions of $0.1 \mathrm{~N} \mathrm{KNO}_{3}$ at $\mathrm{pH} \mathrm{3.4.} \mathrm{Also,} \mathrm{Zemkin} \mathrm{et} \mathrm{al.} \mathrm{(90)} \mathrm{used}$ ac polarography to determine the PCP concentration in photographic gel. The determination was carried out in I M $\mathrm{KNO}_{3}$ at $\mathrm{pH} 6$ on concentrations of PCP ranging from 100 to $600 \mathrm{mg}$ per $\mathrm{kg}$ of gel. 
ELECTROCHEMICAL TECHNIQUES USED IN DEVELOPING A DIRECT METHOD FOR PENTACHLOROPHENOL

The immense amount of methodology for the analysis of PCP indicates the concern of the scientific community about its environmental contamination and toxicity. One overriding need that has not been provided by all of these methods is for a direct method to measure trace contamination of PCP in the waterways and soil of our environment. My research indicates that such a method can be developed using the electrochemical techniques of differential pulse polarography (DPP) and differential pulse voltammetry (DPV). Cyclic voltammetry at the hanging mercury drop electrode (HMDE) was used during the development of this method for PCP to characterize the nature of its electrode reaction. In addition to providing a direct analytical method for PCP, these electrochemical techniques introduce an approach that can serve as a screening analysis for measuring trace amounts of the material. 
Differential Pulse Polarography

DPP was originally developed to essentialiy eliminate charging current contributions from polarographic signals and increase the sensitivity range of polarography. This sensitivity was obtained by altering the normal polarographic signal to create the more sensitive signal produced in DPP. Several articles have been written discussing this technique (91-96).

In normal polarography, a continuous and linearly changing voltage is applied to the DME, and the current that passes through the cell is measured. The polarographic current produced from the reactivity of an electroactive compound consists of faradaic and charging currents. The faradaic current is directly proportional to the concentration of the reactant diffusing to the electrode, while the charging current arises from the capacitor-like characteristics of the electrode. The range of application in normal polarography occurs when the total current has the least contribution from the charging current at approximately $10^{-5}$ molar concentration of the species undergoing reaction at the electrode surface. As a result, normal polarography is generally limited to concentrations above $10^{-5} \mathrm{M}$ for electroactive species. In an attempt to eliminate significant contribu- 
tions from charging current and to improve the sensitivity of their polarographic signal, Barker and Gardner (91) investigated square-wave polarography. Pulse polarography was developed from this investigation. Parry and 0steryoung (92) experimentally confirmed the theory for this methodology, defined the analytical parameters and introduced it to the scientific community as a valuable analytical tool.

When uniform square-wave voltage pulses are imposed on the linear ramp voltage that is produced at the DME in dc polarography, the method is called differential pulse polarography (DPP). Voltage pulses are timed to occur at specific intervals during the lifetime of the mercury drop. When the pulse is applied in the absence of an electrochemical reaction, a current spike occurs from the charging of the double-layer. The double-layer is formed in the following manner (93). When a negative potential is applied to a DME in the presence of an electrolyte, a layer of nonreducible cations forms around each mercury drop. These cations are immediately counterbalanced by a flow of electrons to the surface of the DME to form a layer of electrons. The formation of this double-layer produces a charging current, which decays to zero after a few milliseconds, exhibiting the characteristics of a capacitor. If a diffusion-controlled electro- 
chemical reaction occurs at the surface of the electrode during application of the voltage pulse, the current spike consists of both charging current and faradaic current from the electrochemical reaction. Again, the charging current decays after a few milliseconds, while the faradaic current only decays to the diffusion-limited value for the electroactive species. If the current is sampled before application of the square-wave pulse to obtain a reference current, and after the charging current has decayed to zero, the difference between these two measurements will be due to the faradaic current produced by the electrochemical reaction. This current-sampling technique essentially eliminates charging current from the measured current, and significantly increases the sensitivity range of polarography to $10^{-8}$ molar concentrations for many electroactive species. Furthermore, the shape of the curve obtained from this method is fundamentally a derivative of the de polarographic wave.

In my research, a Princeton Applied Research (PAR) model 174 polarographic analyzer is used in the DPP analysis. The instrument applies a square-wave voltage pulse to the linear dc ramp voltage for 57 milliseconds during the lifetime of each mercury drop. The currentflow is sampled for 17 milliseconds between $t_{1}$ and $t_{2}$, just prior to application of the pulse; and this value is 
stored in the memory of the instrument until the next pulse is applied. In the next pulse, the current-flow is sampled for 17 milliseconds between $t_{3}$ and $t_{4}$ at the end of the pulse period after the charging current has decayed to an insignificant value. Following these two current-sampling intervals, the instrument produces an output signal proportional to the difference between the initial and final current measurements. This readout approximates the derivative of a normal polarographic wave, which yields a peak presentation of the data. Figure 2 shows an example of a square-wave pulse imposed on the ramp voltage during the lifetime of two mercury drops (94). The current-sampling intervals during one pulse period are shown in this illustration.

The same three-electrode system is used in this current-sampling technique of DPP, that is used in dc polarography. In this electrode system, the DME is the working electrode, a silver-silver chloride electrode is the reference electrode and a platinum electrode is the auxilliary electrode. Initially, the system is balanced in the absence of an electrochemical reaction, and no current flows from a faradaic reaction. The initial voltammogram serves as an experimental baseline, which covers the voltage scan of the DPP of interest (97). When an electrochemical reaction occurs in the cell at 


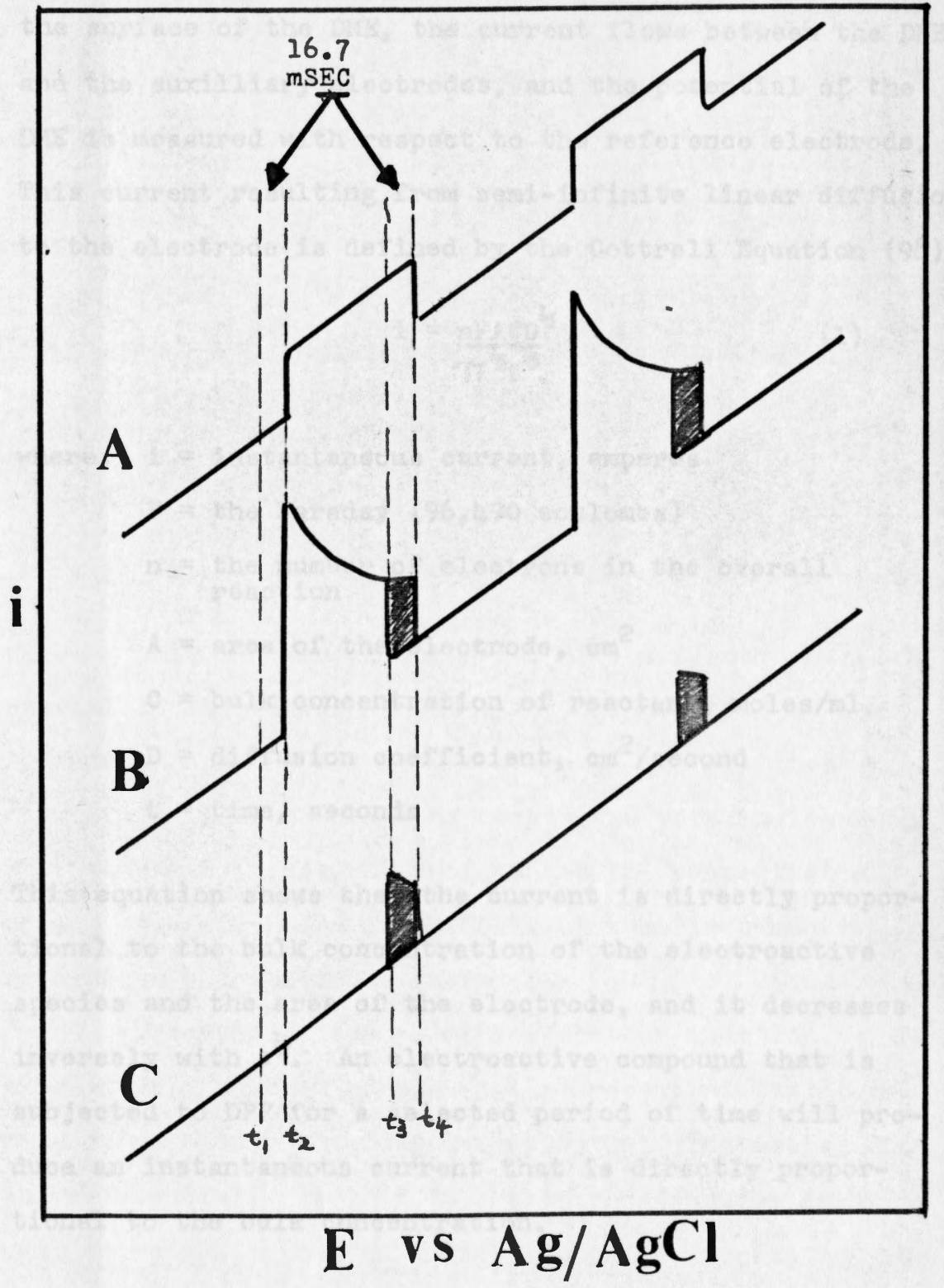

Figure 2. Sequence of events occurring during two mercury drops in DPP. (A) Voltage pulse applied to the dc ramp. (B) Charging and faradaic pulse currents. (C) Faradaic pulse current. 
the surface of the DME, the current flows between the DME and the auxilliary electrodes, and the potential of the DME is measured with respect to the reference electrode. This current resulting from semi-infinite linear diffúsion to the electrode is defined by the Cottrell Equation (98):

$$
i=\frac{n F A C D^{\frac{1}{2}}}{\pi^{\frac{1}{2} t^{\frac{1}{2}}}}
$$

where: $i=$ instantaneous current, amperes

$F=$ the Faraday $(96,490$ coulombs $)$

$\mathrm{n}=\begin{aligned} & \text { the number } \\ & \text { reaction }\end{aligned}$

$A=$ area of the electrode, $\mathrm{cm}^{2}$

$C=$ bulk concentration of reactant, moles $/ \mathrm{ml}$

$D=$ diffusion coefficient, $\mathrm{cm}^{2} /$ second

$t=$ time, seconds

This equation shows that the current is directly proportional to the bulk concentration of the electroactive species and the area of the electrode, and it decreases inversely with $t^{\frac{3}{2}}$. An electroactive compound that is subjected to DPP for a selected period of time will produce an instantaneous current that is directly proportional to the bulk concentration.

$$
i=\mathrm{KC}
$$


The potential of the electrochemical reduction at the DME is related to the formal potential of the electroactive species by the Nernst Equation. In this halfreaction, the oxidized species is reduced by $n$ electrons to give a reduced product:

$$
\mathrm{Ox}+\mathrm{ne}^{-} \rightarrow \operatorname{Red}
$$

The Nernst Equation for this half-reaction is given by the relation:

$$
E=E^{01}+\frac{0.059}{n} \log \frac{(\text { Red })}{(0 x)} \quad\left(\text { at } 25^{\circ} \mathrm{C}\right)
$$

where $\mathrm{E}^{\circ \text { if }}$ is the formal potential of the electrochemical species in the reaction, and $E$ is the potential at the surface of the DME during any stage of the electrochemical reduction. This equation expresses the relation between the potential of the DME surface and the concentrations of the oxidized and reduced forms of the electroactive species at the electrode surface.

The rate of the electron-transfer reaction is an exponential function of the applied potential, and for a cathode reaction, the rate increases with increasing negative potential. For DPP, the electron-transfer reaction rate increases with each succeeding pulse approaching the peak potential for the electrochemical reaction. At the peak potential, the rate of the electron-transfer and 
reduction of the oxidized species is equal to the rate of diffusion of the oxidized species to the electrode from the bulk of the solution.'

In an electrochemical reaction at the surface of the DME, the oxidized form of the reactant predominates until the peak potential is reached. At the peak potential, the concentrations of the oxidized and reduced species are equal, and after the peak potential the reduced form of the electroactive species predominates.

Mercury has several advantages over other types of electrode materials. One important advantage to using the DME for studying cathode reactions in polarography is the high overpotential of mercury for hydrogen ion reduction (99). This means that many reactions of interest will occur at the DME before there is interference from the reduction of the hydrogen ion. Overpotential is defined by Adams (100) as the difference between the equilibrium potential of a cell and the potential required to oxidize or reduce the compound of interest in the cell. Another advantage of the DME is that a new uncontaminated electrode surface is produced with each drop of mercury (101). In addition, the solution is stirred at a controlled and predictable rate with the growth and fall of each new mercury drop. The surface conditions are also reproducible from drop to drop. 
Mercury has the disadvantage of being somewhat difficult t, handle in a flowing system, although at least one group of scientists has studied the feasibility of using the DME in flowing solutions (102).

\section{Differential Pulse Voltammetry}

In electrochemistry, the term "polarography" is conventionally used for describing reactions at a DME (103). Polarography is a specialized technique in the generalized area of voltammetry. As a result, an electrochemical reaction at a solid-state CPE, in which uniform square-wave voltage pulses are imposed on the linear voltage ramp of normal voltammetry, is described as differential pulse voltammetry (DPV).

In DPV, the same type of relationship exists at a CPE between charging and faradaic currents that was found with DPP. Also, the same three-electrode system is used in DPV, except that the carbon paste electrode is substituted for the DME. In adition, the Cottrell Equation defines the current-concentration relationship, and the Nernst Equation defines the potential-concentration relationship for an electrochemical reaction at the CPE. The carbon paste is conveniently prepared by mixing graphite with nujol, and packing the resulting paste into a Teflon cup electrode (104). This electrode gives 
good reproducibility with different batches of carbon paste. Electrochemical reactions of organic compounds tend to cause a film of the reaction product to form on the CPE surface. That is, the surface of the electrode becomes contaminated with adsorbed and electro-deposited materials during an electrochemical reaction. This electrode surface is easily renewed by scraping off a small layer of exposed carbon paste that has been contaminated, and replacing it with new material.

The CPE can be used over a wide range of oxidation and reduction potentials. Adams (105) gives several examples of anode and cathode limits for the CPE in different types of aqueous solutions. This range will vary with ionic strength, and the type of electrolyte used. Since experimental results on PCP in my research were obtained at negative potentials with the stationary $\mathrm{CPE}$, the behavior of the $\mathrm{CPE}$ during reduction of organic compounds is the potential range of most interest here. This electrode is relatively inert, although Adams (106) indicates that a small residual current from the reduction of oxygen will contribute to the background current in the cathode region. Since this residual current produces a long flat region in the cathode output, the reduction current from electroactive compounds can be conveniently superimposed on this residual current. 
A stationary solid electrode, such as the $\mathrm{CPE}$, is more conveniently used in a flowing system than the DME. The mechanical logistics to using a DME in a flowing system for detecting trace contaminants are difficult to overcome (107).

Cyclic Voltammetry at the Hanging Mercury Drop Electrode

Adams (108) has given an excellent discussion on cyclic voltammetry (CV) and most of the description on this method will be developed from his material. According to Adams, CV was originally developed by A. Sevcik to study electrochemical reactions.

In CV, a triangular-wave voltage is used as opposed to the linear ramp voltage of de polarography. A rapid potential sweep is made over the positive or negative voltage regions of interest, and then, the direction of scanning is reversed over the same potential range. The voltage signal is applied to the HMDE, and the cyclic voltage sweep is completed in a few seconds.

Figure 3 shows the triangular voltage pattern that is applied to the HMDE, and the general shape of the cyclic voltamogram obtained from this scan technique (109-110). When the voltage scan is started at point $A$, the current will remain near the origin, and only residual 

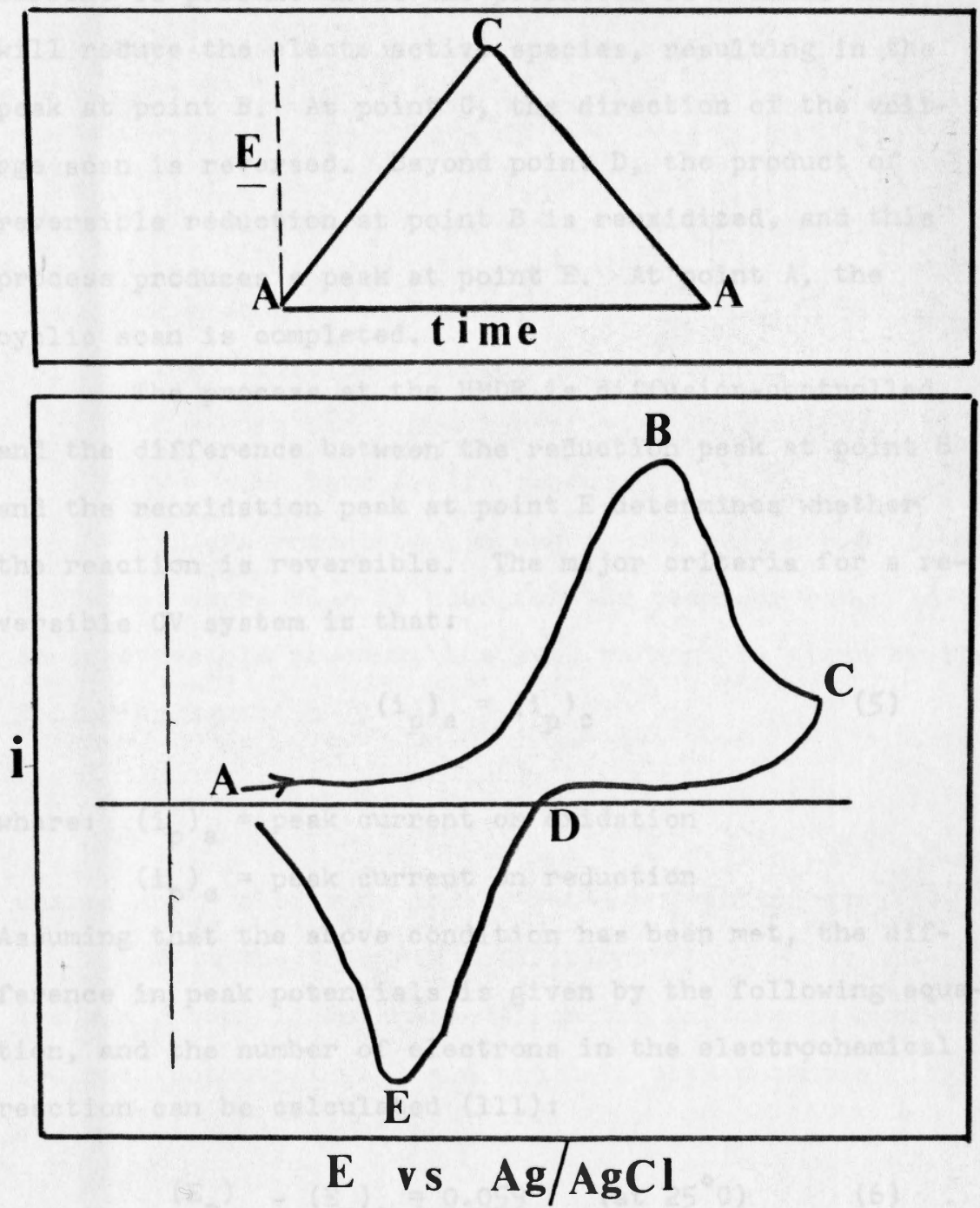

Figure 3: Triangular wave-form applied to HMDE, and the general shape of the cyclic voltammogram. 
current is present until the potential is reached that will reduce the electr sactive species, resulting in the peak at point $B$. At point $C$, the direction of the voltage scan is reversed. Beyond point $D$, the product of reversible reduction at point $B$ is reoxidized, and this process produces a peak at point $E$. At point $A$, the cyclic scan is completed.

The process at the HMDE is diffusion-controlled, and the difference between the reduction peak at point $B$ and the reoxidation peak at point $E$ determines whether the reaction is reversible. The major criteria for a reversible CV system is that:

$$
\left(i_{p}\right)_{a}=\left(i_{p}\right)_{c}
$$

where: $\left(i_{p}\right)_{a}=$ peak current on oxidation

$$
\left(i_{p}\right)_{c}=\text { peak current on reduction }
$$

Assuming that the above condition has been met, the difference in peak potentials is given by the following equation, and the number of electrons in the electrochemical reaction can be calculated (III):

$$
\left(E_{p}\right)_{a}-\left(E_{p}\right)_{c}=\frac{0.059}{n} \quad\left(\text { at } 25^{\circ} \mathrm{C}\right)
$$

where: $\left(E_{p}\right)_{a}=$ potential of the oxidation peak

$$
\left(E_{p}\right)_{c}=\text { potential of the reduction peak }
$$


When the reduction process is reversible, the peak current is given by the equation (112):

$$
1_{p}=2.67 \times 10^{5} \mathrm{n}^{\frac{3}{3}} \mathrm{AD}^{\frac{1}{2}} \mathrm{C} v^{\frac{3}{2}} \quad\left(\text { at } 25^{\circ} \mathrm{C}\right)
$$

where: $\mathrm{n}=$ number of electrons in electrochemical reaction

$$
\begin{aligned}
& A=\text { area of electrode, } \mathrm{cm}^{2} \\
& D=\text { diffusion coefficient, } \mathrm{cm}^{2} / \text { second } \\
& C=\text { bulk concentration of reactant, moles/ml } \\
& v=\text { scan rate, } \nabla 0 l t s / s e c o n d
\end{aligned}
$$

If the reduction process is not reversible, a different expression is used for the peak current. In an irreversible process, the peak current is given by the following equation (113):

$$
i_{p}=3.01 \times 10^{5} \mathrm{n}\left[\alpha_{\mathrm{n}}\right]^{\frac{1}{2}} \mathrm{AD}^{\frac{1}{2}} \mathrm{Cv}^{\frac{3}{2}} \quad\left(\text { at } 25^{\circ} \mathrm{C}\right)
$$

where: $n_{a}=$ electrons in the rate-controlling step

$$
\boldsymbol{\alpha}=\text { the transfer coefficient }
$$

The $\left[\alpha n_{a}\right]$ term is determined from the difference between the peak potential $\left(E_{p}\right)$ and the half-peak potential ( $\left.E_{\frac{p}{2}}\right)$ by the following equation:

$$
E_{p}-E_{\frac{r}{2}}=-1.857\left(\frac{0.026}{n_{a}}\right) \quad\left(\text { at } 25^{\circ} \mathrm{C}\right. \text { ) }
$$

These two equations for $i_{p}$ in the reversible and irreversible CV processes can be reduced to the following 
simple expression for quantitating a given electroactive species in a particular solvent:

$$
1_{p}=K C
$$

where $K$ is a constant that can be evaluated with standard solutions. This equation gives a direct relationship between peak current in CV and the concentration of the electroactive species.

This CV technique is generally employed to study charge-transfer rates, and to define the chemical and electrochemical processes that are taking place at the electrode during an electrochemical reaction. This technique was used in the study of PCP to investigate the chemical and electrochemical processes that were occurring at the electrode during the reduction of PCP.

The PAR 174 polarographic analyzer was used in my CV analysis of PCP. Since CV is performed in quiet solutions, the rates of reversible reactions are considered diffusion-controlled. In $\mathrm{CV}$, products from electrochemical reduction are still available at the electrode surface for reoxidation on the reverse cycle, because of the fast sweep rates employed. As a result, this reaction may produce peak currents from charge-transfer processes alone, or from charge-transfer processes coupled with chemical follow-up reactions. Thus, CV will often provide 
direct evidence for intermediate, and other types of chemicai follow-up reactions. 
CHAPTER IV

EXPERIMENTAL

Instrumentation

All DPP, DPV and CV results in the investigation of PCP were obtained with a PAR Model 174 Polarographic Analyzer equipped with a PAR Model 174 Drop Timer. This drop timer precisely dislodges the mercury drop at a preselected drop time and with a minimum disturbance to the solution. A one-second drop time was selected for all studies on PCP.

The voltammograms produced from this investigation of PCP were recorded on a MFE 815, X-Y Plotamatic Recorder. A digital voltmeter was used to accurately determine the voltage applied to the working electrode. In DPP, the working electrode was a DME, which was made from a very fine glass capillary tubing. Tygon tubing led from this capillary tubing to a reservoir filled with mercury. The height of the reservoir was adjustable for altering the size and flow characteristics of the mercury drop. Mercury is forced through the capil- 
lary by gravity to provide a continuous flow for reproducible drop area.

In DPV, the working electrode was a CPE, which was prepared by a procedure described by Adams (114). A uniform paste is formed by mulling together 15 of graphite (Acheson, Grade 38 or equivalent) and $9 \mathrm{ml}$ of Nujol. This paste is hand-packed into a well-like depression of a $3 \mathrm{~mm}$ i.d. Teflon cup electrode, and this assembly is used as the working electrode in the DPV procedure.

In CV, the working electrode was a PAR Model 9323 $\mathrm{HMDE}$ : In this assembly, the mercury drop hangs from a glass capillary tube connected to a reservoir containing mercury. A plunger attached to a micrometer dial is advanced into the reservoir until a measured amount of mercury is displaced. A mercury drop is formed on the end of the capillary for each CV determination. Platinum and gold working electrodes were also investigated for $\mathrm{CV}$ analysis.

In bulk electrolysis, the working electrode consisted of a mercury pool contacted by a platinum electrode located below the mercury surface. The mercury pool was continuously agitated with a small magnetic stirring bar during electrolysis to inhibit film formation on the surface of the mercury by the electrolysis reactants and products. 
The same reference and auxilliary electrodes were used with all of these working electrodes. A silversilver chloride reference electrode containing $1.0 \mathrm{M} \mathrm{KCl}$ was custom constructed in the laboratory for these experiments. This electrode exhibited a potential of +0.230 volts against the normal hydrogen electrode in a saturated solution of quinhydrone at $\mathrm{pH} 7$ (115). A platinum wire with platinum gauze attached was used as an auxilliary electrode. The auxilliary electrode was isolated in a glass tube sealed with porous Vycor for the bulk electrolysis process. Cell electrolyte and buffer were used in this electrode assembly.

The cell consisted of a 30-ml beaker containing a snug-fitting lucite cover with four holes to support the components of the cell assembly. The reference electrode was positioned between the working and auxilliary electrodes in the cell assembly. Prepurified nitrogen was passed through a gas scrub bottle containing distilled water into the cell. All potentials obtained with this assembly are reported against the aqueous silversilver chloride reference electrode.

Ultraviolet spectra of PCP in 1-propanol were obtained in a $0.1 \mathrm{~cm}$ cell with a Beckman ACTA MVII Spectrophotometer.

Infrared spectra were obtained on Perkin-Elmer 
Models 21 and 283 Infrared Spectrophotometers. The Model 21 instrument was equipped with a Perkin-Elmer 6X Microsampling Unit for condensing the sample beam onto a very small region. As a result, IR spectra can be obtained on very small samples. $\mathrm{KBr}$ pollets containing $\mathrm{PCP}$ were used with the micro-sampling unit, and Nujol mulls of PCP were used with the Model 283 instrument.

Electron impact mass spectra were obtained with a Dupont Model 21-490B Mass Spectrometer at an ionizing current of $70 \mathrm{eV}$.

Gas Chromatograms were obtained on a PerkinElmer Model 900 Gas Chromatograph. This GC was equipped with a flame ionization detector and an effluent splitter for trapping micro-samples. A 6' $\times 8 \mathrm{~mm}$ o.d. glass column containing 7\% SP-1000 on chromosorb G-HP was used for the PCP analysis. The GC column was operated with a helium flow of $30 \mathrm{ml} /$ minute, an oven temperature of $225^{\circ} \mathrm{C}$, an injection port temperature of $225^{\circ} \mathrm{C}$ and a manifold temperature of $255^{\circ} \mathrm{C}$.

Melting points of materials were determined with a Model 6406-H Thomas-Hoover Melting Point Apparatus.

Other Equipment

Paper chromatograms were developed on $46 \times 46 \mathrm{~cm}$ 
Whatman no. 1 paper in a $30 \times 30 \times 60 \mathrm{~cm}$ glass tank. Other accessories used in this procedure were a 9 " solvent dish, paper hangers and hooks, a forced-draft oven, an ultraviolet lamp, and a spray flask for dispensing the chromogenic agent onto the chromatogram.

Thin-layer chromatograms were developed on $20 \mathrm{x}$ $20 \mathrm{~cm}$ pre-coated silica gel plates of glass from Brinkmann in: Instruments, Inc. Other accessories used in this proceaure were a $4 \times 12 \times 9^{\prime \prime}$ developing tank, a forceddraft oven, an ultraviolet lamp and a glass atomizer for spraying the chromogenic agent onto the chromatograms.

Purification of PCP after electrolysis was made on Amberlite XAD-4 colums. This material from Rohm and Haas, Co. is a cross-linked polystyrene copolymer (20-50 mesh beads) of high porosity (50 vol. \%), high surface area $\left(850 \mathrm{~m}^{2} / \mathrm{g}\right)$ and an inert, hydrophobic surface (116). Laboratory adsorption was made in a 25-ml buret containing $8.5 \mathrm{~cm}$ resin.

\section{Reagents}

Only analytical reagent grade chemicals were used in this investigation, and they were used without further purification. The PCP was obtained from Eastman Chemical Co. (lot F2C), and had a melting point of $187-188.5^{\circ} \mathrm{C}$. 
The purity of this sample of PCP was more fully investigated by obtaining its IR spectrum from $4000-700 \mathrm{~cm}^{-1}$. The spectrum was found to be identical with the spectrum published by Aldrich for $99+\%$ pure PCP (117). In addítion, no impurities could be identified in this sample of PCP from its mass spectrum. The data in Table 3 was obtained from this analysis, and shows the molecular weights of PCP, that are obtained from the normal distribution of the chlorine isomers.

\section{TABLE 3}

Data from the Mass Spectrum of Pentachlorophenol

$\begin{array}{lcc}\text { Species } & \frac{\mathrm{m} / \mathrm{e}}{\text { Relative Abundance }} \\ \mathrm{m}^{+} & 264 & 61.5 \\ \mathrm{~m}^{+}+2 & 266 & 100.0 \\ \mathrm{~m}^{+}+4 & 268 & 65.0 \\ \mathrm{~m}^{+}+6 & 270 & 21.1 \\ \mathrm{~m}^{+}+8 & 272 & 3.4 \\ \mathrm{~m}^{+}+10 & 274 & 0.2\end{array}$

A $1.0 \mathrm{mM}$ stock solution of PCP was prepared fresh daily to be used in the electrochemical studies. The PCP was prepared in the buffer system under investigation, and successive incremental additions of this stock solution were transferred to the sample cell by a 25- $\mu 1$ pi- 
pette during the electrochemical analyses. Stock solutions were only prepared from distilled water that was stored in glass to minimize contamination from the container.

The phosphate buffer system used with the DME and the CV methods was prepared from a 50:50 mixture of $0.01 \mathrm{M}$ monosodium and disodium phosphate containing 0.01 $\mathrm{M} \mathrm{NaCl}$ as an electrolyte. $\mathrm{NaOH}$ was also used to adjust the $\mathrm{pH}$ of this solution.

The phosphate buffer system used in bulk electrolysis was prepared from a $50: 50$ mixture of $0.5 \mathrm{M}$ monosodium and disodium phosphate containing $0.5 \mathrm{M} \mathrm{NaCl}$. The $\mathrm{pH}$ of this solution was also adjusted with $\mathrm{NaOH}$. Other buffer systems that were investigated for. possible use in the electrochemical methods were $0.1 \mathrm{M}$ glycine, $0.05 \mathrm{M}$ borate and $0.01 \mathrm{M} \mathrm{NH}_{4} \mathrm{Cl} / \mathrm{NH}_{3}$ buffers.

Two different solvent systems were used in the paper chromatographic investigation of PCP. A mixture of isopiopanol- $\mathrm{NH}_{4} \mathrm{OH}-\mathrm{H}_{2} \mathrm{O} \quad(20: 1: 2)$ was used for one solvent system, and a $2 \%$ aqueous acetic acid solution was used for the other system.

Tetrazotized benzidine reagent prepared from a $50: 50$ mixture of $0.5 \%$ benzidine in dilute $\mathrm{HCl}$ and $10 \%$ $\mathrm{NaNO}_{2}$ in water was used as the chromogenic agent for the paper chromatograms. 
The solvent systems used in TLC for investigating the behavior of electrolyzed PCP were (1) n-hexane, (2) chloroform, (3) chloroform-acetic acid (100:1, v/v), (4) benzene-ethyl acetate $(10: 1, v / v)$ and (5) acetone- $1 \mathrm{~N} \mathrm{NaOH}$ $(94: 6, v / v)$.

A copper sulfate-pyridine reagent was prepared from $5 \mathrm{~g}$ of copper sulfate and $5 \mathrm{~g}$ of pyridine mixed and diluted to $100 \mathrm{ml}$ with a $(10: 1)$ water-acetone mixture. This solution was sprayed on the developed TLC plates to detect PCP and its possible electrolysis products.

A silver nitrate reagent was prepared from a mixture of $0.5 \mathrm{~g} \mathrm{AgNO}_{3}$ in $5 \mathrm{ml} \mathrm{H} \mathrm{H}_{2} \mathrm{O}$ and $100 \mathrm{ml} \mathrm{2-phenoxy-}$ ethanol, that was diluted to a liter with acetone. This reagent was also used in TLC to detect PCP and its possible electrolysis products.

\section{Electrochemical Procedures}

The following procedure was used for obtaining the differential pulse polarograms on PCP at the DME. The operating conditions for DPP were selected on the polarographic analyzer for a $2-\mathrm{mV} / \mathrm{sec}$ scan rate, a $1.5-\mathrm{V}$ scan range, a 25-mV pulse modulation amplitude, a DIFF. PULSE operating mode, a minimum current range and a $I$ second drop time for the DME. The recorder was set to give $200 \mathrm{mV} / \mathrm{in}$. on the $\mathrm{X}$-axis and $\mathrm{I} \mathrm{V/in.} \mathrm{on} \mathrm{the} \mathrm{Y}$-axis. 
The area of the mercury drop from the DME was determined each day by collecting mercury drops over a selected period of time and weighing the mercury. The weight per drop of mercury, the equation for the volume of a sphere and the equation for the area of a sphere were used in this calculation.

The background current produced on each new preparation of buffer solution was recorded prior to the addition of PCP. This was accomplished by transferring $25 \mathrm{ml}$ of $0.01 \mathrm{M}$ phosphate buffer solution into the electrochemical cell, inserting the electrode assembly, outgassing the solution for 10 minutes with prepurified nitrogen and linearly varying the voltage at $2 \mathrm{mV} / \mathrm{sec}$ over the cathode potential range of the DME. Nitrogen was passed over the buffer solution during the voltage scan.

After the background current profile was determined on the buffer, 25- $\mu 1$. aliquots of PCP were injected into the cell by successive standard additions. Each new addition raised the PCP concentration of the cell by one micromolar. The faradaic current produced from the reduction of PCP at the DME was recorded after each addition of PCP to the cell. The sample was prepared for each DPP analysis by the same procedure that was outlined for the buffer. Each polarographic scan was com- 
pleted in five minutes with a total analysis time of 15 minutes for each determination.

In the DPV procedure with the CPE, the same operating conditions previously used with the DME system were selected on the polarographic analyzer. The buffer strength was increased to $0.1 \mathrm{M}$ phosphate buffer, and the same procedure used with the DME was also followed here. the voltamograms were developed with a 1.0 second pulse rate. After each analysis, the carbon paste at the end of the electrode was replaced to insure a new surface for the next run.

In $C V$ at the HMDE, the experimental settings on the polarographic analyzer were selected for scan rates ranging from 50 to $500 \mathrm{mV} / \mathrm{sec}$, a pulse modulation amplitude of $25 \mathrm{mV}$, a dc operating mode and full scale current sensitivities ranging from 1 to $5 \mu \mathrm{A}$. The recorder was set a $200 \mathrm{mV} /$ in. on the $\mathrm{X}$-axis and $\mathrm{I} \mathrm{V} / \mathrm{in}$. on the $\mathrm{Y}$-axis. The area of the mercury drop used in the CV procedure was determined by dialing a selected number of scale divisions of mercury drops from the HMDE and weighing. This weight was used to calculate the area of the mercury drop displaced per scale division advanced by the dial. The dial was advanced two scale divisions to displace a $1.608 \times 10^{-2} \mathrm{~cm}^{2}$ exposed area of mercury for these experiments on PCP with CV. 
Cyclic voltamograms were obtained on $0.01 \mathrm{M}$ phosphate buffer and on $0.5 \mathrm{mM}$ PCP in this buffer system. these samples were transferred to the 25-ml electrochemical cell, the electrode assembly was inserted, the sólutions were outgassed for 10 minutes with prepurified nitrogen, the dial of the HIDE was advanced two scale divisions to obtain the hanging mercury drop and the voltage was linearly varied at selected velocities to the cathode potential limit of the $\mathrm{HMDE}$ and reversed back to the starting point of the scan. Nitrogen was continuously passed over the electrolysis solution during the voltage scan. Techniques used in this investigation included scanning different sections of the complete cyclic range independently, scanning at different velocities and at different current sensitivities, and beginning the scans at different points on the reduction and oxidation cycles.

Unsuccessful attempts were made to obtain cyclic voltammograms of PCP at platinum and gold working electrodes in $0.1 \mathrm{M}$ glycine buffer containing $0.1 \mathrm{M} \mathrm{NaCl}$. The PCP samples were handled by the same techniques with these electrodes that were used for the HMDE system.

In the bulk electrolysis procedure, $0.5 \mathrm{M} \mathrm{PCP}$ was transferred to the electrolysis cell, a mercury pool was added, the electrode assembly and a small magnetic stirrer were inserted, and a fixed potential of -1.1 V 
versus $\mathrm{Ag} / \mathrm{AgCl}$ was applied to the working electrode by a McGee-Pedersen Potentiostat. The cell solution was outgassed with prepurified nitrogen and stirred by magnetic stirrer throughout the electrolysis process. PĆP solutions were subjected to 24-hour and 72-hour periods of electrolysis by this procedure.

Following electrolysis, the cell products were isolated from the buffer and electrolyte by acidifying with phosphoric acid, and extracting with ether. This material was used for the subsequent investigation of electrolysis products.

In another method, an Amberlite XAD-4 Adsorbent in a column was used for isolating the PCP materials from the buffer and electrolyte (116). In this method, the electrolysis solution was acidified with $\mathrm{H}_{3} \mathrm{PO}_{4}$ to produce a white precipitate, which was washed onto the column with water. This PCP material was supposed to adhere to the beads, while the buffer, electrolyte and acid were being washed from the column with water. Unfortunately, a significant amount of the precipitated PCP material was washed through the column with the water, and this method was subsequently abandoned.

The PCP materials, which remained on the column after the water wash, were eluted with 2-propanol, concentrated to dryness on a steam bath, and used in the in- 
vestigation for reduction products of PCP.

DC polarography at the DME was also investigated

in an attempt to establish an electrochemical method for PCP. The operating conditions for this method were selected on the polarographic analyzer for 10 and $20 \mathrm{mV} / \mathrm{sec}$ scan rates, a $1.5-\mathrm{V}$ scan range, a $25-\mathrm{mV}$ pulse modulation amplitude, a DC operating mode, a minimum current range and a one-second drop time for the DME. Concentrationdependent polarograms were obtained for 0.15 and $0.25 \mathrm{mM}$ concentrations of PCP. The polarograms obtained on lower concentrations of PCP were difficult to evaluate, and this procedure was not found to be sensitive enough to measure ppm levels of PCP.

Paper and TLC Procedures

In the paper chromatography procedure for electrolyzed PCP, the materials were spotted on the paper at selected intervals along a starting line that was drawn an inch from the bottom of the sheet. Concentrations of 30,50 and $100 \mu \mathrm{g}$ of electrolyzed PCP, $30 \mathrm{mg}$ of 3,5dichlorophenol and $60 \mathrm{mg}$ of a 50:50 mixture of electrolyzed PCP and 3,5-dichlorophenol were applied along this line. The resulting chromatogram was furled into a cylinder and the overlapping sides were fastened to each 
other with three equally-spaced glass hooks. This cyc linder was suspended from two hooks on a pressure rod into the center of the chromatography tank, so that the bottom edge of the paper was dipping to the bottom of a 9 " dish containing the solvent. The top was placed on the tank and the chromatogram was developed in the isopropanol- $\mathrm{NH}_{4} \mathrm{OH}-\mathrm{H}_{2} \mathrm{O}$ solvent system for 20 hours, and in the $2 \%$ acetic acid solvent system for 4 hours.

After development, the solvent front of each chromatogram was marked before removal from the tank. Then, the chromatogram was unfurled, dried in a forceddraft oven at $80^{\circ} \mathrm{C}$ for 3 minutes, observed under UV light to locate any possible fluorescent compounds and was sprayed with tetrazotized benzidine solution to locate any reduction products of PCP. The 3,5-dichlorophenol gave a brown color after coupling with the tetraazotized benzidine reagent.

In the TLC procedure for electrolyzed PCP, the materials were spotted on the TLC plate at selected intervals along a starting line that was drawn li $\mathrm{cm}$ from the bottom of the plate. Concentrations of 5, 25, 50 and $100 \mu g$ of electrolyzed PCP, $50 \mu g$ of 3,5-dichlorophenol and $50 \mathrm{mg}$ of standard PCP were spotted along this line on the TLC plate.

After application of these materials, each TLC: 
plate was placed in a chromatography tank containing the deyeloping solvent and its vapors in a saturated state. The top was placed on each tank and the chromatogram was developed in the $n$-hexane solvent system (55) for 7 minutes; and in the chloroform (54), benzene-ethylacetate (10:1); chloroform-acetic acid $(100: 1)$ (24) and IN $\mathrm{NaOH}-$ acetone $(6: 94)$ (57) solvent systems for approximately 45 minutes.

After separation, the plates were dried in a cold stream of air, and examined under UV light for possible fluorescent spots. Following this examination, the compounds on the TLC plate were detected with a $\mathrm{AgNO}_{3}$ (57), and a copper sulfate-pyridine reagent (13) in each solvent system. After application of the $\mathrm{AgNO}_{3}$ spray, the TLC plate was dried in a forced-draft oven at $80^{\circ} \mathrm{C}$ for 2 minutes and exposed to UV light for 15 minutes to develop the brown spots produced from the formation of the silver salts of the phenols. The copper sulfatepyridine reagent was sprayed on the TLC plate after air-drying to obtain brown spots on a light blue background. The color was produced from the formation of the copper salts of the phenols.

A compound having the same $R_{f}$ value as standard PCP, and an unknown spot at a $R_{f}$ of 0.9 were located in the chloroform solvent system. The PCP ran below an $R_{f}$ 
of 0.5 in this solvent system. A preparative TLC plate with a thick sorbent layer of silic: gel was used in an attempt to isolate this unknown compound for IR analysis with a beam-condensing unit.

A 20-mg sample of electrolyzed PCP was spread across the bottom $1 \frac{1}{2} \mathrm{~cm}$ baseline on the TLC plate and developed in the chloroform solvent. The plate was airdried and the upper edge of the PCP band was located as a dark band under UV light and marked. Then, all of the silica gel above this dark band and to the solvent front was carefully scraped off the glass plate, and extracted several times with ether. The ether extract was taken to dryness to obtain a small amount of yellow oily-appearing material. Some of this material was mixed into a $\mathrm{KBr}$ pellet and subjected to IR analysis with the beamcondensing unit.

The remainder of the ether extract was applied to the Florisil column in a small amount of methylene chloride. The column was thoroughly washed with pentane to remove possible oily contaminants from the sample on the Florisil. This pentane extract was taken to dryness, mixed with a KBr pellet and analyzed by IR with a beamconcensing unit. 


\section{CHAPTER V}

\section{RESULTS AND DISCUSSION}

The Differential Pulse Polarography Investigation of - Pentachlorophenol with the Dropping Mercury Electrode

The behavior of PCP during a voltage scan over the cathode region of the DME was investigated with DPP. This investigation showed that PCP is electrochemically reduced at a peak potential of approximately -0.8 volts relative to $\mathrm{Ag} / \mathrm{AgCl}$, and that $\mathrm{DPP}$ can be used as a direct method for PCP concentrations down to $0.27 \mathrm{ppm}$. Concentration dependent polarograms were obtained on from 1 to $10 \mu \mathrm{M}$ of PCP under clean, controlled conditions in pH 7 through 11 phosphate buffer solutions. Figure 4 shows the well-defined peaks that were obtained on from 4 to 10 alM ( 1.1 to $2.7 \mathrm{ppm}$ ) PCP in $\mathrm{pH} 9$ phosphate buffer solution at the DME.

The Ag/AgCl electrode was chosen as the reference electrode in this investigation, because it is considered highly reproducible and reliable (118). It is also easy to construct and use in the laboratory.

The DME was chosen as the worling electrode in 


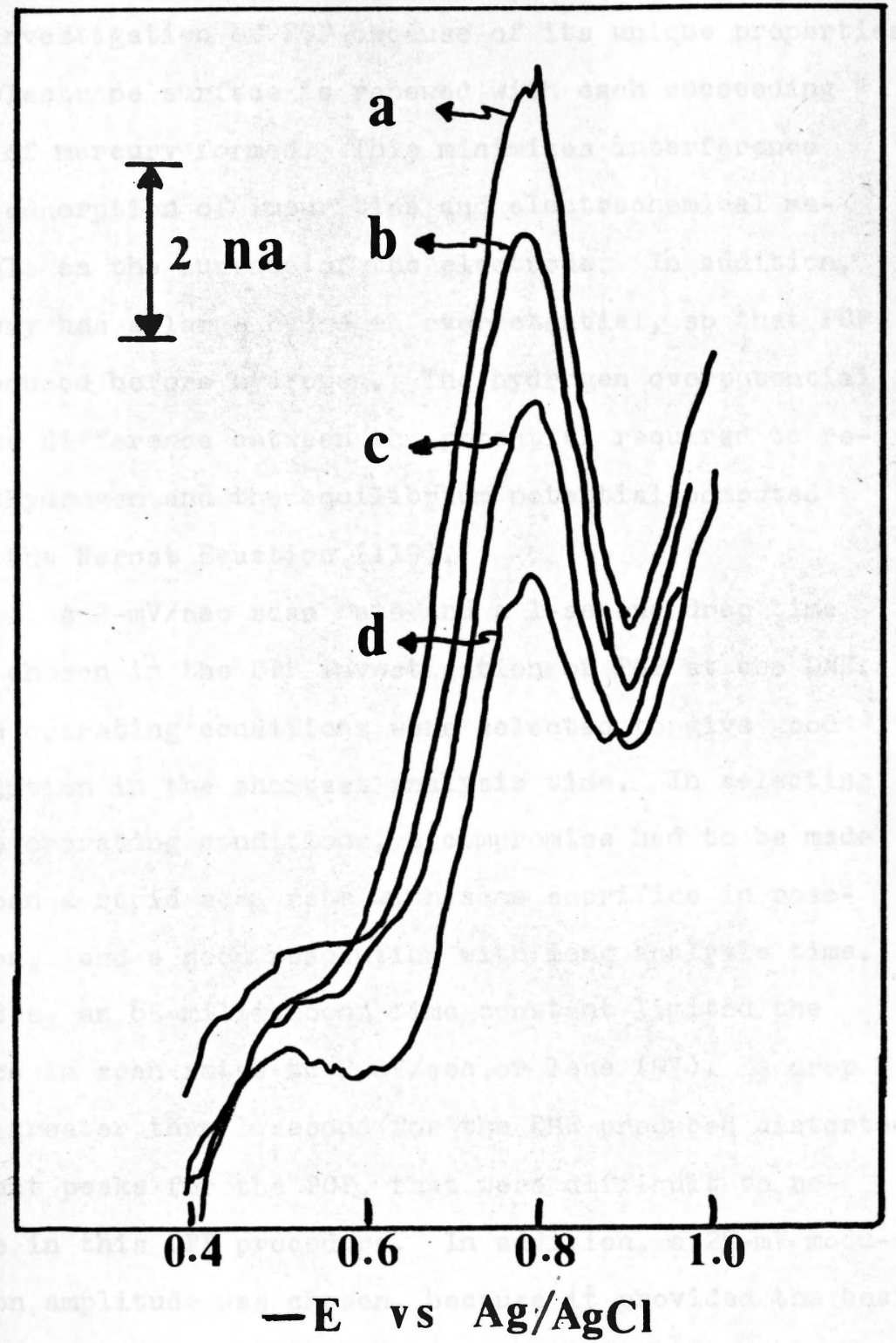

Figure 4: Differential pulse polarograms of PCP at the DME in $0.01 \mathrm{M}$ phosphate buffer, $\mathrm{pH} 9.0$. (a) $10 \mu \mathrm{M}$ (b) $8 \mu \mathrm{M}$ Tc) $6 \mu \mathrm{M}$ (d) $4 \mu \mathrm{M}$ 
the investigation of PCP because of its unique properties. The electrode surface is renewed with each succeeding drop of mercury formed. This minimizes interference from adsorption of impurities and electrochemical materials on the surface of the electrode. In addition, mercury has a large hydrogen overpotential, so that PCP is reduced before hydrogen. The hydrogen overpotential is the difference between the potential required to reduce hydrogen and the equilibrium potential computed from the Nernst Equation (119).

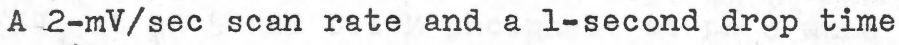
were chosen in the DPP investigation of PCP at the DME. These operating conditions were selected to give good resolution in the shortest analysis time. In selecting these operating conditions, a compromise had to be made between a rapid scan rate with some sacrifice in resolution, and a good resolution with long analysis time. Besides, an 85-millisecond time constant limited the choice in scan rates to $2 \mathrm{mV} / \mathrm{sec}$ or less (97). A drop time greater than 1 second for the DME produced distorted current peaks for the PCP, that were difficult to resolve in this DPP procedure. In addition, a $25-\mathrm{mV}$ modulation amplitude was chosen, because it provided the best resolution in the framework of the other conditions selected in this analysis.

At the beginning of this investigation, $20.1 \mathrm{M}$ 
glycine buffer system that is commonly used in DPP studies on biological compounds was selected for this DPP study of PCP, but the current contribution from the buffer or buffer background appeared to change within a short time of preparation. As a result, several other buffer media were examined to find a system that was compatible with PCP, that gave a reproducible background within a reasonable time after preparation, and that gave the least background interference in the analysis of PCP. Buffer systems of $0.05 \mathrm{M}$ borate at $\mathrm{pH} 10,0.01$ $\mathrm{M} \mathrm{NH} / 4 \mathrm{Cl}_{3}$. at $\mathrm{pH} 9$ and $0.1 \mathrm{M}$ phosphate at $\mathrm{pH} 8$ were investigated in this survey. These buffers were discussed for electrochemical use by Adams (120). The phosphate buffer background current was reproducible with time, but it had a higher background than the glycine buffer. The other two buffer systems had such high backgrounds that they could not be used for this analysis. Low PCP concentrations tend to be masked by a high buffer background. In an investigation of the phosphate buffer background, separate DPP scans were made of the $\mathrm{NaOH}, \mathrm{NaCl}, \mathrm{NaH}_{2} \mathrm{PO}_{4}$, and $\mathrm{Na}_{2} \mathrm{HPO}_{4}$ components of this buffer system in aqueous solutions. All of these components contributed to the phosphate buffer background. These results indicated that a lower buffer strength should reduce the buffer background. Subsequently, PCP 
was investigated in $0.05 \mathrm{M}, 0.02 \mathrm{M}, 0.01 \mathrm{M}$ and $0.005 \mathrm{M}$ phosphate buffer solutions to find the optimum buffer strength for the study of PCP. As expected, the buffer background was reduced by reducing the strength of the buffer and lower concentrations of PCP could be measured. A concentration-dependent peak was obtained for one $\mu \mathrm{M}$ of PCP in $0.01 \mathrm{M}$ phosphate buffer, and all subsequent PCP analyses by DPP at the DME were made in this buffer system.

$\mathrm{NaCl}$ was used as an electrolyte in these aqueous buffer systems to minimize migration of electroactive species, so that diffusion-controlled conditions are maintained (121).

The effects of $\mathrm{pH}$ on the reduction behavior of PCP are shown in Figure 5. Initially, the $0.01 \mathrm{M}$ phosphate buffer was adjusted to $\mathrm{pH} 7$ with $\mathrm{NaOH}$, and concentration dependent polarograms were obtained on from 1 through $10 \mu \mathrm{M}$ of PCP. This process was repeated for each succeeding unit of $\mathrm{pH}$ through $\mathrm{pH}$ 11. The data collected from this study and the correlation coefficient at each pH are included in Table 4. Excellent concentration dependent linearity was found at each of these $\mathrm{pH}$ conditions with correlation coefficients of 0.98 or better for most of the data. In general, as the $\mathrm{pH}$ of the buffer was raised, the current-concentration sensitivity increased over this $\mathrm{pH}$ renge. The only exception 


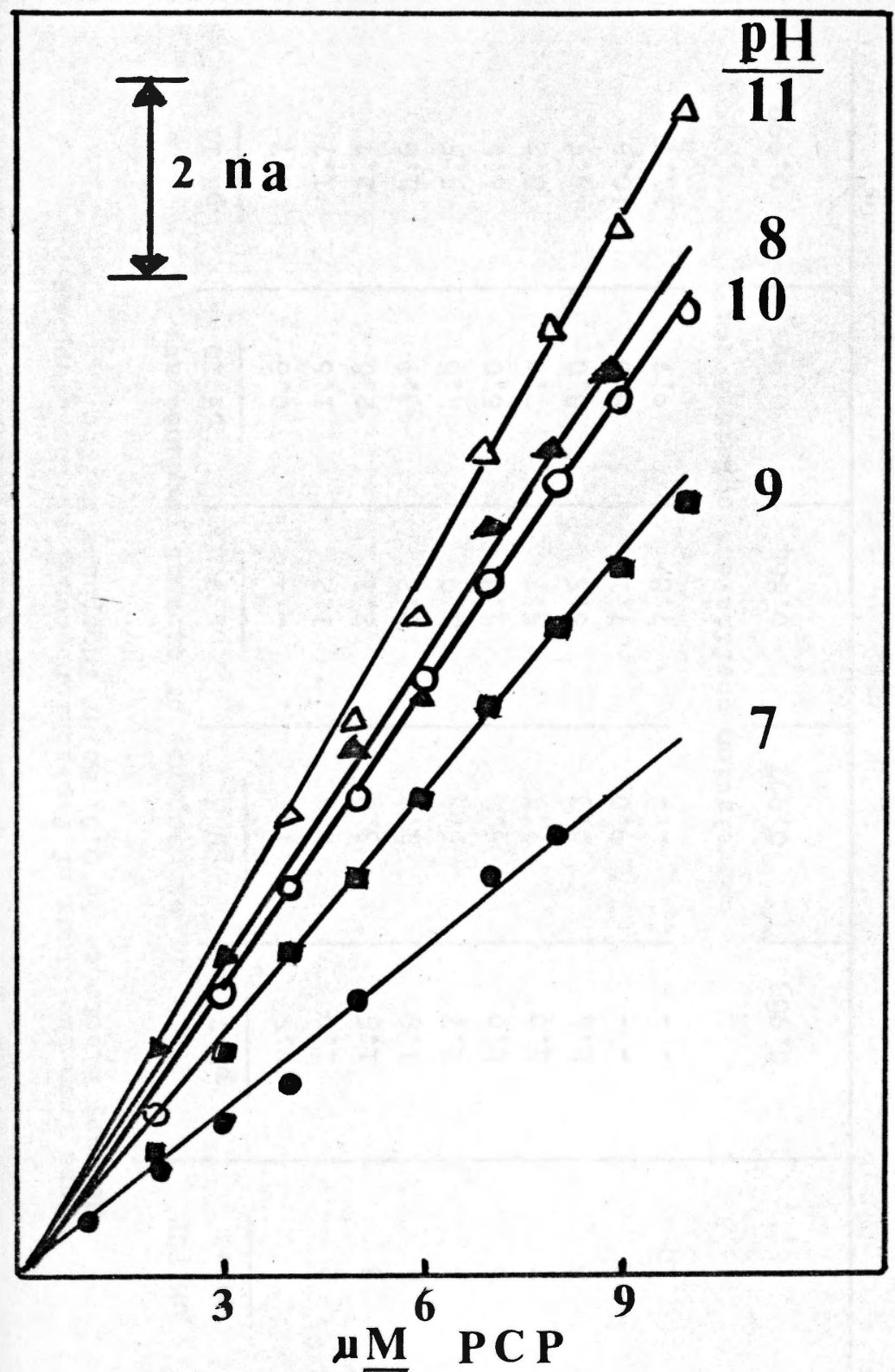

Figure 5: The effects of $\mathrm{pH}$ on differential pulse polarograms of PCP in $0.01 \mathrm{M}$ phosphate buffer at the DME. 


\section{TABLE 4}

Data from the Study of Pentachlorophenol at the Dropping Mercury Electrode in 0.01 Molar Phosphate Buffer

\begin{tabular}{|c|c|c|c|c|c|}
\hline $\begin{array}{l}\text { MM PCP } \\
\text { used }\end{array}$ & $\mathrm{pH} 7$ & $\begin{array}{l}\text { pH } 8 \\
\text { pramper }\end{array}$ & $\begin{array}{l}\mathrm{pH} 9 \\
\text { eurent }\end{array}$ & $\begin{array}{l}\text { ced at: } \\
\mathrm{pH} 10\end{array}$ & $\mathrm{pH} 11$ \\
\hline 1 & 0.5 & 1.1 & - & 0.6 & 0.7 \\
\hline 2 & 1.0 & 2.3 & 1.2 & 1.6 & 1.7 \\
\hline 3 & 1.5 & 3.2 & 2.2 & 2.8 & 2.7 \\
\hline 4 & 1.9 & 4.0 & 3.2 & 3.9 & 4.6 \\
\hline 5 & 2.7 & 5.3 & 4.0 & 4.8 & 5.5 \\
\hline 6 & 4.0 & 5.8 & 4.8 & 6.0 & 6.6 \\
\hline 7 & 4.0 & 7.5 & 5.7 & 7.0 & 8.2 \\
\hline 8 & $4 \cdot 4$ & 8.3 & 6.5 & 8.0 & 9.5 \\
\hline 9 & - & 9.0 & 7.1 & 8.8 & 10.5 \\
\hline \multirow[t]{3}{*}{10} & -- & -- & 7.8 & 9.7 & 11.7 \\
\hline & \multicolumn{5}{|c|}{ correlation coefficient obtained at: } \\
\hline & 0.983 & 0.997 & 0.864 & 0.999 & 0.999 \\
\hline
\end{tabular}


was found at $\mathrm{pH} 8$, which showed a greater currentconcentration sensitivity for PCP, than was found in either the pH 9 or 10 buffer systems. Variability in current sensitivity of from 2.16 to $4.40 \mathrm{nA}$ per ppm PCP was found. This type of behavior strongly indicates changing diffusion rates, which suggests that ion-pairing might be involved. It would seem reasonable that there would be a difference in the diffusion coefficients of the undissociated phenol, the ion-paired phenol and the phenoxide ion, and this difference should be reflected in PCP behavior at different $\mathrm{pH}$ conditions. This explanation would seem logical, since the diffusion coefficient is the only term in the Cottrell Equation that could be varying. In this investigation, PCP was found to be electrochemically inactive to reduction below $\mathrm{pH} 6.5$.

There is no ready explanation for the behavior of PCP in the pH 8 phosphate buffer system. There are apparent differences in the background current occurring with changes in $\mathrm{pH}$, and these differences could affect the adsorption of the ion-pair species at the electrode surface. Whatever is occurring does not affect the 8 buffer system to the same extent as the higher $\mathrm{pH}$ buffer systems. At any rate, the purpose of investigating the behavior of PCP in this buffer system under different $\mathrm{pH}$ conditions was to find the optimum $\mathrm{pH}$ for developing an electro-analytical method for $\mathrm{PCP}$. In accordance with 
these results, the pH 8 phosphate buffer system should be selected. This system would give optimum current sensitivity and mild $\mathrm{pH}$ conditions.

The unusual behavior of PCP in the $\mathrm{pH} 8$ phosphate buffer system was reaffirmed by a second analysis. The same current sensitivity of $1.1 \mathrm{nA}$ per $\mu \mathrm{M}$ of PCP was found from the linear current-concentration relationship in both experiments.

An investigation was made to determine whether the phosphate buffer containing the PCP was contributing to the peak current of PCP. Phosphate buffer containing no PCP was added to the cell solution by successive incremental additions in the same manner that had been used for the addition of PCP. Each increment of phosphate buffer added to the cell increased the concentration of the 0.25 milliequivalents of phosphate buffer already in the cell by $2.5 \times 10^{-7}$ milliequivalents. After each addition, a peak polarogram was obtained on the cell solution. No buffer contribution to the peak current of PCP was found, even after 10 increments of buffer were added to the cell. Subsequent addition of PCP to the cell solution produced a current peak where no peak had been produced with the 10 increments of buffer. This experiment shows that the buffer containing the PCP makes no significant contribution to the $P C P$ current signal at the 
concentration used in these experiments.

The Differential Pulse Voltammetry Investigation of Pentachlorophenol with the Carbon Paste Electrode

Studies of the redox properties of PCP at the CPE were made with DPV. Such a system would give versitility to a differential pulse method for PCP in situa-: tions where the DME would be inconvenient to use. For example, a CPE could be easily adapted for use as an amperometric detector for PCP in a flowing system. The DPV technique with the CPE system can be used as a direct method for PCP concentrations down to $0.27 \mathrm{ppm}$ in a $\mathrm{pH} 8$ phosphate buffer system. Concentration-dependent voltammograms were obtained on from 1 to $5 \mu \mathrm{M}(0.27$ to $1.33 \mathrm{ppm})$ of PCP under clean, controlled conditions in a $0.1 \mathrm{M}$ phosphate buffer system. Figure 6 shows the well-defined peaks that were obtained on PCP at the CPE.

The same reference electrode and instrumental operating conditions were used for both the DME and the CPE system, and for the same reasons. A one-second pulse time was chosen in the DPV investigation of PCP at the CPE.

The CPE was used as the solid working electrode in DPV, because of its desirable characteristics. This electrode has a large hydrogen overpotential, the elec- 
83

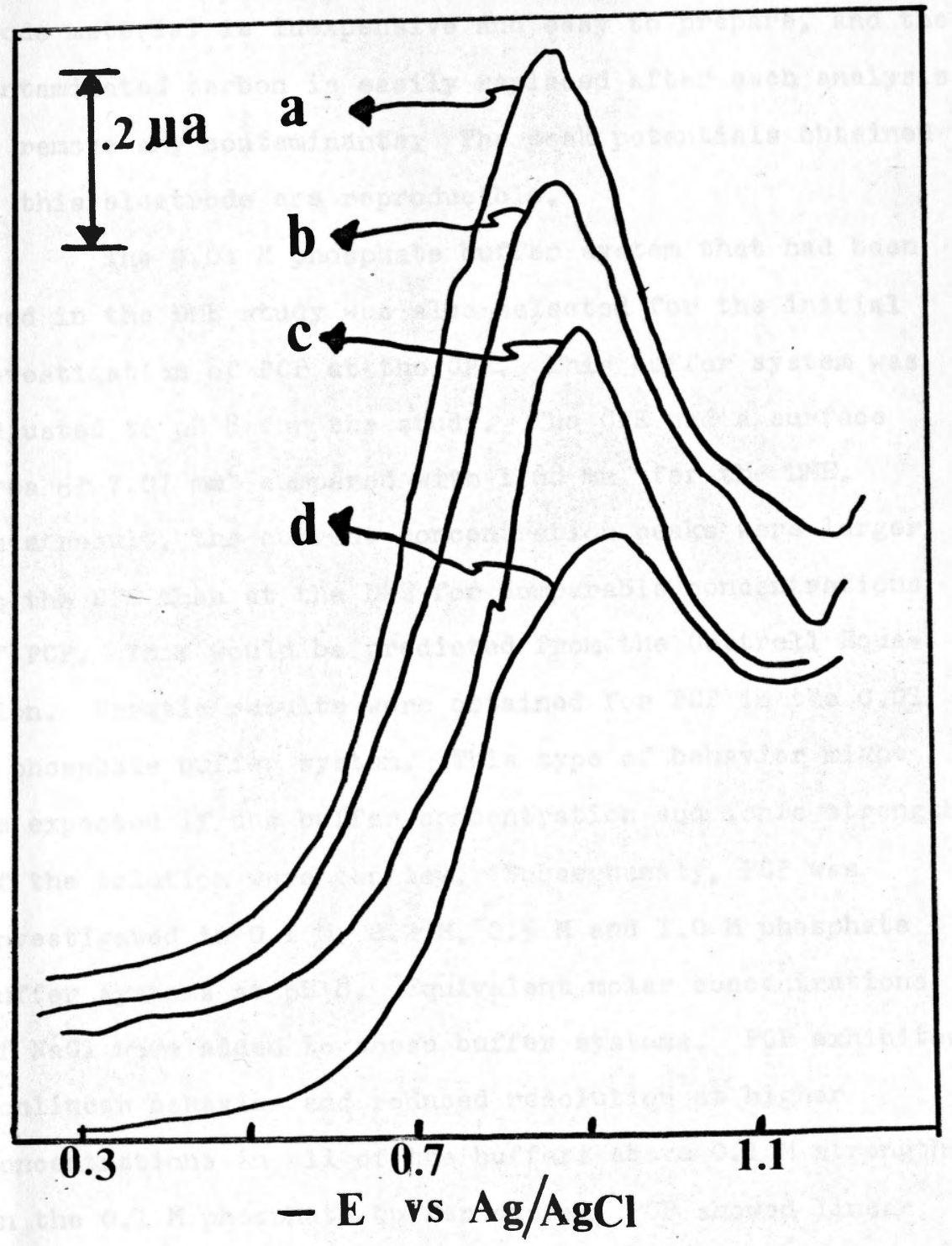

Figure 6: Differential Pulse Polarograms of PCP at the CPE in $0.1 \mathrm{M}$ phosphate buffer, $\mathrm{pH} 8.0$ (a) $5 \mu \mathrm{M}$ $\begin{array}{llll}\text { (b) } 4 \mu \underline{M} & \text { (c) } 2 \mu \underline{M} & \text { (d) } 1 \mu M\end{array}$ 
trode material is inexpensive and easy to prepare, and the contaminated carbon is easily replaced after each analysis to remove any contaminants. The peak potentials obtained at this electrode are reproducible.

The $0.01 \mathrm{M}$ phosphate buffer system that had been used in the DME study was also selected for the intial investigation of PCP at the CPE. This buffer system was adjusted to $\mathrm{pH} 8$ for the study. The CPE had a surface area of $7.07 \mathrm{~mm}^{2}$ compared with $1.68 \mathrm{~mm}^{2}$ for the DME. As a result, the current-concentration peaks were larger at the CPE than at the DME for comparable concentrations of PCP. This would be predicted from the Cottrell Equation. Erratic results were obtained for PCP in the 0.01 M phosphate buffer system. This type of behavior might be expected if the buffer concentration and ionic strength of the solution were too low. Subsequently, PCP was investigated in $0.1 \mathrm{M}, 0.2 \mathrm{M}, 0.5 \mathrm{M}$ and $1.0 \mathrm{M}$ phosphate buffer systems at pH 8 . Equivalent molar concentrations of $\mathrm{NaCl}$ were added to these buffer systems. PCP exhibited nonlinear behavior and reduced resolution at higher concentrations in all of the buffers above $0.1 \mathrm{M}$ strength. In the $0.1 \mathrm{M}$ phosphate buffer system, PCP showed linear current-concentration response through a $5 \mu \mathrm{M}$ concentration range, and this buffer system was used for the DPV analysis of PCP at the CPE. Figure 7 shows a graphical representation of the current-concentration relationship 


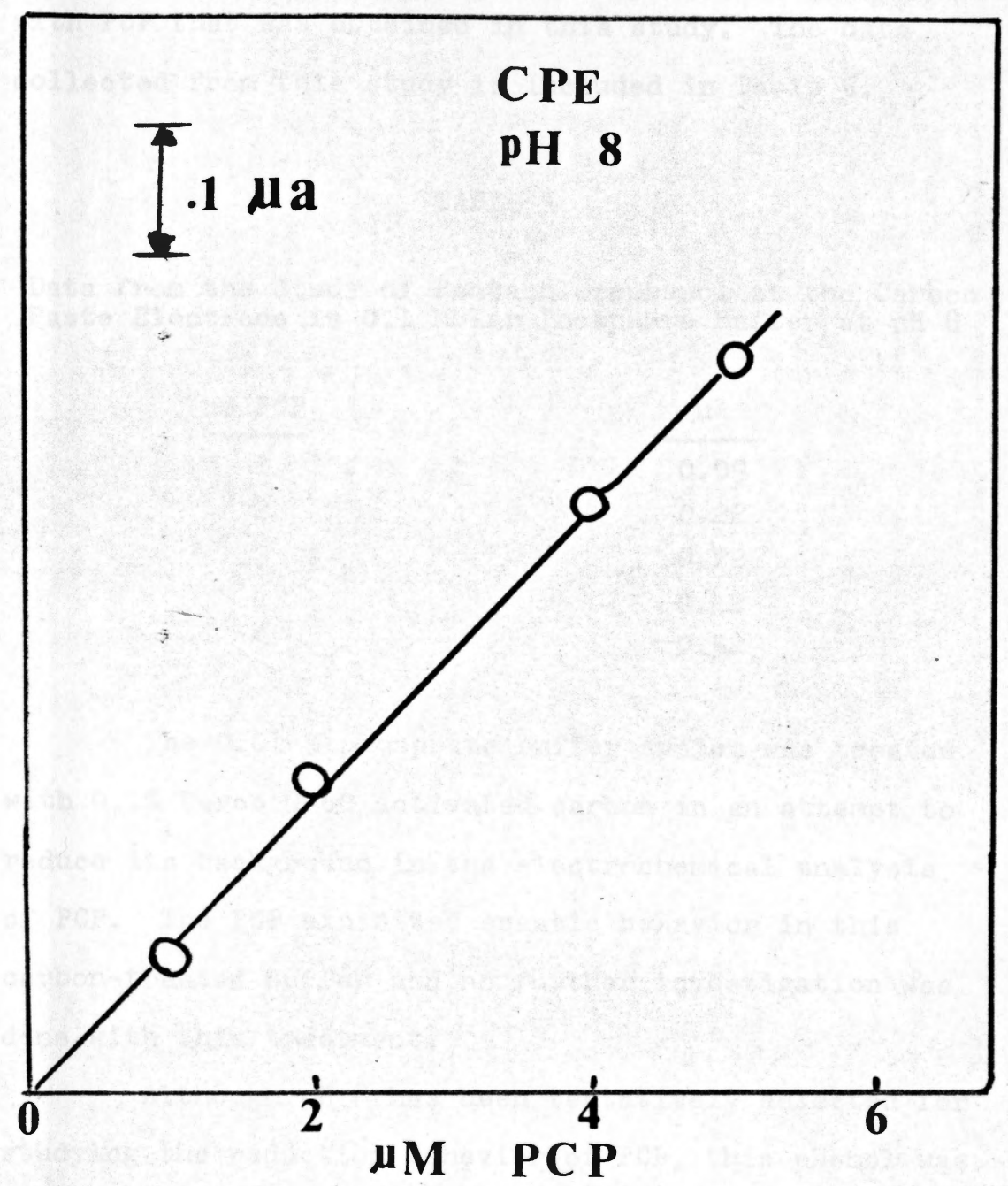

Figure 7: Current-concentration relationship for $\mathrm{PCP}$ at the CPE in $0.1 \mathrm{M}$ phosphate buffer, $\mathrm{pH} 8.0$. 
with PCP that was obtained in this study. The data collected from this study is included in Table 5.

\section{TABLE 5}

Data from the Study of Pentachlorophenol at the Carbon Paste Electrode in 0.1 Molar Phosphate Buffer at $\mathrm{pH} 8$

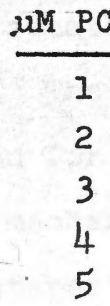

\begin{tabular}{l}
$31 A$ \\
\hline 0.09 \\
0.22 \\
0.22 \\
0.42 \\
0.52
\end{tabular}

The $0.01 \mathrm{M}$ phosphate buffer system was treated with $0.1 \%$ Darco G-60 activated carbon in an attempt to reduce its background in the electrochemical analysis of PCP. The PCP exhibited erratic behavior in this carbon-treated buffer and no further investigation was done with this treatment.

Although $\mathrm{pH} 8$ has been tentatively selected for studying the reduction behavior of PCP, this phenol was also investigated in $1 \mathrm{M} \mathrm{NH}_{4} \mathrm{Cl} / \mathrm{NH}_{3}$ buffer at $\mathrm{pH} 9$ and $0.01 \mathrm{M}$ phosphate buffer at $\mathrm{pH}$ 10. The background of the $\mathrm{NH}_{4} \mathrm{Cl} / \mathrm{NH}_{3}$ buffer system was too high to obtain useful results. The peak currents were not found to be linear with PCP concentration in the $\mathrm{pH} 10$ buffer system. The reason for this behavior is not known. 
The Cyclic Voltametry Investigation of Pentachlorophenol with the Hanging Mercury Drop Electrode

The behavior of PCP during a cyclic voltage scan over the cathode region of the HMDE was investigated with CV. This study was made to identify the type of electrochemical reaction that was occurring at the HMDE, and to determine something about the reversibility of the PCP reduction. The $\mathrm{CV}$ procedure was only used in this investigation for making qualitative evaluations of these electrode mechanisms with PCP. Figure 8 shows the region of interest in the cyclic voltammogram that was obtained at a $200 \mathrm{mV} / \mathrm{sec}$ scan rate on PCP at the HMDE. During the cathode potential sweep of the PCP solution, a sharp and highly symmetrical peak was produced at -0.4 volts and a broad rounded peak appeared at approximately -0.8 volts versus $\mathrm{Ag} / \mathrm{AgCl}$. Both of these peaks were coupled with their respective oxidation peaks during the anode sweep of the cycle. The reduction peak at -0.4 volts was separated from its oxidation peak by $25 \mathrm{mV}$, and it exhibited the typical adsorption-desorption behavior of a non-faradaic peak with its symmetrical shape about the peak potential (122). The concentrationdependent peak of interest in this method was at -0.8 volts versus $\mathrm{Ag} / \mathrm{AgCl}$, and it exhibited behavior that is typical for a faradaic electron-transfer reaction. The 


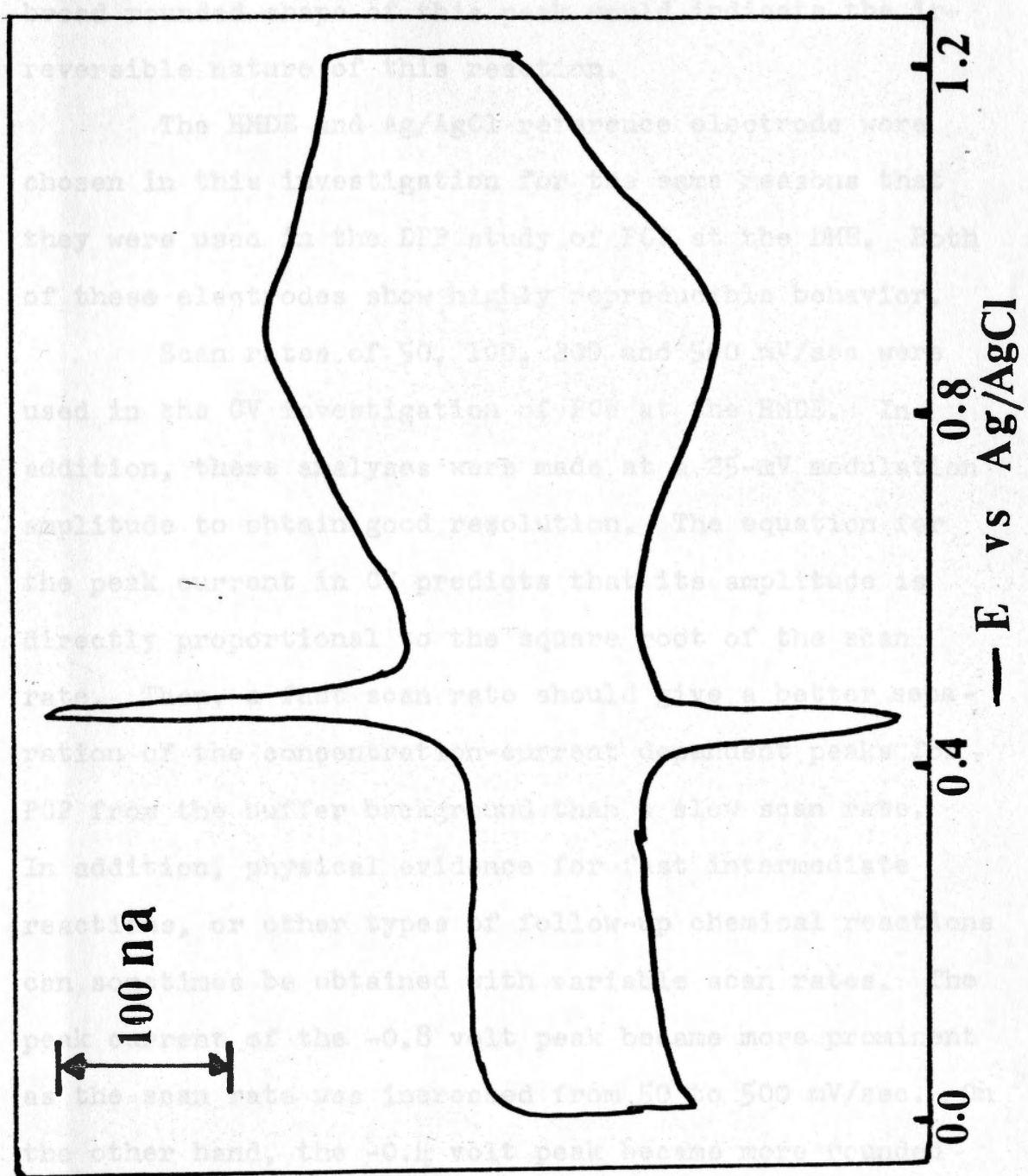

Figure 8: Cyclic voltammogram of $0.5 \mathrm{mM}$ PCP in $0.01 \mathrm{M}$ phosphate buffer, $\mathrm{pH} 10.0$. Scan rāte 0.2 volts/second. 
broad rounded shape of this peak would indicate the irreversible nature of this reaction.

The HMDE and $\mathrm{Ag} / \mathrm{AgCl}$ reference electrode were chosen in this investigation for the same reasons that they were used in the DPP study of PCP at the DME. Both of these electrodes show highly reproducible behavior. Scan rates of $50,100,200$ and $500 \mathrm{mV} / \mathrm{sec}$ were used in the CV investigation of PCP at the HMDE. In addition, these analyses were made at a $25-\mathrm{mV}$ modulation amplitude to obtain good resolution. The equation for the peak current in CV predicts that its amplitude is directly proportional to the square root of the scan rate. Then, a fast scan rate should give a better separation of the concentration-current dependent peaks for PCP from the buffer background than a slow scan rate. In addition, physical evidence for fast intermediate reactions, or other types of follow-up chemical reactions can sometimes be obtained with variable scan rates. The peak current of the -0.8 volt peak became more prominent as the scan rate was increased from 50 to $500 \mathrm{mV} / \mathrm{sec}$. On the other hand, the -0.4 volt peak became more rounded and less prominent as the scan rate was increased. This behavior is reflective of the non-faradaic character of the -0.4 volt peak (122). No evidence was found from any of these scan rates that would indicate any transient 
intermediate or other type of subsequent chemical reaction of PCP is occurring.

The CV investigation of PCP at the HMDE was made in $0.01 \mathrm{M}$ phosphate buffer containing $0.01 \mathrm{M} \mathrm{NaCl}$, because this buffer system was previously used for the DME study of PCP. Cyclic voltammograms were obtained on PCP solutions that were adjusted from $\mathrm{pH} 7$ through 11 by consecutive units. These analyses were made to determine if changes in $\mathrm{pH}$ produced any observable changes in the behavior of PCP at the HMDE. No changes were found in the CV pattern of PCP below pH 11. There is some distortion in the $\mathrm{CV}$ peaks at $\mathrm{pH}$ 11, which is attributed to the high basicity of the system. The $0.01 \mathrm{M}$ phosphate buffer did not show the CV current peaks at -0.4 and -0.8 volts that were produced by the PCP. Initially, concentrations of $1,2,3,5,10,100$, 150,200 and $500 \mu \mathrm{M}$ of PCP were investigated with CV. These cyclic voltamograms were difficult to interpret at PCP concentrations below $500 \mu \mathrm{M}$, and all subsequent analyses were made on 500 pM of PCP.

Cyclic voltammograms were obtained on PCP from different starting points of the voltage cycle to determine if any of the current peaks were affected. In one experiment, a cathode scan was made from -l.1 volts to a switching potential at -1.3 volts, back to a switch- 
ing potential at 0.0 volts, and to -1.1 volts for completion of the cycle. In another experiment, a cathode scan was made from -0.6 volts to a switching potential at -1.1 volts, and back to 0.0 volts. In the final experiment, the cathode scan was made from -0.6 volts to a switching potential at -1.2 volts, and back to a switching potential at 0.0 volts, to a switching potential of -0.48 volts. The scan was reversed again at -0.48 volts back to 0.0 volts, so that the reduction peak at -0.4 volts was obtained in a couple with its oxidation peak. None of the current peaks for PCP were visibly affected by starting the voltage scans at different points in the cycle.

CV studies were made on PCP by dividing the cyclic voltammogram into three segments. The first segment was scanned from 0 to $-0.6 \mathrm{~V}$ and cycled back to 0 . The reduction peak at $-0.4 \mathrm{~V}$ coupled with its oxidation peak were isolated in this voltage range. The second segment was scanned from -0.6 to $-1.1 \mathrm{~V}$ and cycled back to $-0.6 \mathrm{~V}$. The reduction peak at $-0.8 \mathrm{~V}$ coupled with its oxidation peak were isolated in this voltage range. The third segment was scanned from $-1.1 \mathrm{~V}$ to the cut-off voltage of the HMDE at approximately $-1.9 \mathrm{~V}$ versus $\mathrm{Ag} / \mathrm{AgCl}$ and reversed back to $-1.1 \mathrm{~V}$. No useful information was obtained from this segment of the voltammogram, because it 
showed general adsorption. Each of these segments was examined in detail at different current sensitivities and scan rates to obtain the cyclic voltammograms used in the study.

CV was also used as a quick procedure for investigating the electrochemical behavior of PCP at the gold and platinum working electrodes. These electrodes were substituted for the HMDE in this investigation. PCP reduction could not be detected at either of these electrodes.

The DC Polarography Investigation of Pentachlorophenol

DC polarography was used to investigate the reduction behavior of PCP before any other electrochemical procedures were tried. This technique was not sensitive enough to measure the ppm levels of PCP contaminating the environment, and other electrochemical procedures had to be investigated for this purpose.

DC polarography was also used to investigate the number of electrons that were involved in the reduction of $\mathrm{PCP}$ at $-0.8 \mathrm{~V}$ versus $\mathrm{Ag} / \mathrm{AgCl}$. $\mathrm{A} \mathrm{DC}$ polarogram was developed on $1 \mathrm{mM}$ PCP in $0.1 \mathrm{M}$ phosphate buffer for this purpose, but a good baseline could not be obtained in this buffer system. This determination can only be made 
from a good baseline.

Investigation of Reduction Products of Pentachlorophenol

Bulk electrolysis by controlled potential coulometry was used to investigate the reduction products of PCP. Evidence for the reduction of PCP was obtained from the electrochemical techniques that were used in this study.

A mercury pool covering the bottom of the cell was used as the working electrode. This provided a large electrode area for the reduction of PCP during the bulk electrolysis process. A magnetic stirring bar was used to agitate the mercury during electrolysis to minimize the thickness of the diffusion layer near the electrode surface, and to increase the rate of PCP reduction at the electrode during electrolysis. A potential of -1.1 volts was applied to the working electrode during the electrolysis of a $0.05 \mathrm{M}$ solution of PCP for 72 hours. This potential was 0.3 volts more cathodic than the faradaic reduction peak at -0.8 volts, and during electrolysis the current dropped from 3 to $2 \mathrm{~mA}$. Faradaic calculations would predict that essentially all of the PCP in the cell should have been converted to its reduction product(s) during this period, if nothing interferred with the 
electrochemical reduction.

Ide et al. (19) found that microorganisms in soil decompose PCP by reductive dechlorination and that the ortho and para chlorines are lost more often than the meta chlorines in this process. Wedemejer et al. (123) reported that PCP preferentially undergoes reductive dechlorination at the ortho and para positions in the presence of sulfur and hydrogen gas. The evidence in these two reports would suggest that the ortho and para chlorines would be preferentially lost during the electrochemical reduction of PCP.

No reduction products were found from a GC investigation of this electrolyzed PCP. Even though the column containing $7 \%$ SP-1000 on chromosorb G-HP was not very sensitive to $P C P$, it should have detected any reduction products of PCP that were present in significant concentrations. A flame ionization detector was used for this GC analysis.

The melting point of the electrolyzed PCP was slightly lower than the purified PCP, and showed a greater melting point range. Melting point determination of the electrolyzed PCP showed a range from 177 to $182^{\circ} \mathrm{C}$. This may be caused by trace contamination from the phosphate buffer and $\mathrm{NaCl}$ electrolyte that were used in the electrolysis process. The electrolyzed PCP was obtained 
by extraction into ether from an acidified electrolysis mixture.

No reduction products were found from a paper chromatography investigation of electrolyzed PCP. The two solvent systems used in this investigation had boen routinely used for the investigation of phenolics. Both electrolyzed PCP and 3,5-dichlorophenol were examined in these solvent systems. Tetraazotized benzidine would only couple with a phenol that contained a hydrogen site on the ring. The 3,5-dichlorophenol gave a dark brown spot with the benzidine. Several concentrations of electrolyzed PCP were investigated with paper chromatography, but all of the concentrations gave negative results with benzidine for other phenols.

No reduction products were found in an IR analysis of the electrolyzed PCP. The spectrum obtained from this analysis was identical to the Aldrich IR Spectrum for PCP (117).

No reduction products were found in a TLC investigation of the electrolyzed PCP. The electrolysis mixture was run in several solvent systems, and the plates were sprayed with $\mathrm{AgNO}_{3}$ and $\mathrm{CuSO}_{4}$ reagents, which formed colored salts with the phenol group. Any positive spots found with these reagents were isolated as bands on preparative TLC plates, and investigated by an IR micro- 
sampling procedure without and with pre-treatment on a Florisil column to remove any contaminants. No IR spectrum for any possible reduction product of PCP was found by this procedure.

This investigation did not elucidate the nature of the PCP reduction product. The surface of the mercury pool may have been passivated even with constant agitation, which prevented significant reduction of PCP. 


\section{CONCLUSIONS}

The results from this electrochemical study of PCP indicate that DPP can be used as a direct procedure for determining trace concentrations of PCP down to $0.27 \mathrm{ppm}$. The DME and CPE have been used with this procedure to reduce PCP in a basic phosphate buffer solution. This is a rapid procedure requiring only fifteen minutes per analysis. In adition, the approach is uniquely different from any of the existing analytical methods for PCP.

The results from the CV analysis of PCP at the HMDE show a non-faradaic adsorption-desorption peak at -0.4 volts and a peak at -0.8 volts versus $\mathrm{Ag} / \mathrm{AgCl}$ that is typical for a faradaic electron-transfer reaction. Electron transfer followed by a chemical reduction would be indicated, although attempts to produce this reduction material for study by controlled potential coulometry were unsuccessful. The extremely sensitive techniques of GC, IR, TLC and paper chromatography were used in an attempt to detect and identify any reduction products from the coulometric experiment. This investigation did not elucidate the nature of the PCP reduction product(s). 
These results indicate that no significant reduction of PCP occurred during electrolysis. The surface of the mercury pool may have been passivated to reduction of PCP. 


\section{BIBLIOGRAPHY}




\section{BIBLIOGRAPHY}

1. R. N. Adams, "Electrochemistry at Solid Electrodes", Marcel Dekker, Inc., New York, pp. 363-365, 1969.

2. A. Bevenue and H. Beckman, Residue Rev., 19, 83 (1967).

3. A. Bevenue, M. L. Emerson, L. J. Casarett and W. L. Yauger, J. Chromatogr., 38, 467 (1968).

4. J. A. Wyllie, J. Gabica, W. W. Benson and J. Yoder, Pestic. Monit. J., 2, 150 (1975).

5. B. G. Henshaw, J. W. W. Morgan and N. Williams, J. Chromatogr., 110, 37 (1975).

6. W. T. Haskins, Anal. Chem,, 23, 1672 (1951).

7. E. C. Weinbach, Biochemistry, 43, 393 (1957).

8. J. E. Gordon, "Control of Communicable Diseases in Man". The American Public Health Association, New York, p. 209 (1965).

9. K. Erne, Acta Pharmacol. Toxicol., 14, 158 (1958).

10. G. R. Wallin, Anal. Chem., 22, 1208 (1950).

11. H. van Langeveld, J.Assoc. Off. Anal. Chem., 58, $19(1975)$.

12. T. Narahu, J. Hayakawa, H. Takahashi and Y. Ishida, Shokuhin Eiseigaku Zasshi, 6, 417 (1965): CA 64: 14861 .

13. J. R. Davies and S. T. Thuraisingham, J. Chromatogr., 35, 43 (1968).

14. K. W. Cheng and W. W. Kilgore, J. Food Sci., 3I, $742(1963)$.

15. D. Gordon, Med. J. Aust., 43, 485 (1956). 
16. Monsanto Chemical Co., Technical Bulletin No. SC-6, St. Louis, Missouri, July 1960.

17. R. W. Armstrong, E. R. Eichner, D. E. Klein, W. F. Barthel, J. V. Bennett, V. Jonsson, P. H., H. Bruce and L. E. Loveless, J. Pediatr., 75, 317 (1969).

18. G. Yip, J. Assoc. Off. Anal. Chem, 47, 1116 (1964).

19. A. Ide, Y. Niki, F. Sakamoto, I. Watanabe, and H. Watanabe, Agric. Biol. Chem.9. 36, 1937 (1972).

20. F. B. Lipinskii, I. A. Prokhorov, Mater Vses

Sovesheh Defoliatsii Desikatsii, 1, 400 (1974): CA 85: 117862d

21. V. H. Parker, Biochem. J., 69, 306 (1958).

22. E. C. Weinbach and J. Garbus, J. Biol. Chem, 240, 1811 (1965).

23. P. Smejtek, K. Hsu and W. H. Perman, Biophys. J., 16. $319(1976)$.

24. J. Saarikoski and K. Kaila, Bull. Environ. Contam. Toxicol., 17, 40 (1977).

25. R. A. Kehoe, W. Deichmann-Gruebler and K. V. Kitzmiller, J. Ind. Hyg. Toxicol., 21, 160 (1939).

26. H. Bergner, P. Constantinidis, and J. H. Martin, Can. Med. Assoc. J., 92, 448 (1965).

27. J. B. Chapman and P. Robson, Lancet, I, 1266 (1965).

28. T. H. McGavack, L. J. Boyd, F. V. Piccione, and R. Terranova, J. Ind. Hyg. Toxicol., 23, 239 (1941).

29. C. J. Goodnight, Ind. Eng. Chem., 34,868 (1942).

30. American Conference of Governmental Industrial Hygienists, J. Occup. Med., 5, 191 (1963).

31. A Bevenue, T. J. Haley and H. W. Klemmer, Bull. Environ. Contam. Toxicol., 2, 293 (1967).

32. A. Bevenue, J. Wilson, I. J. Casarett and H. W. Klemmer, Bull. Environ. Contam. Toxicol., 2, 319 (1967). 
33. K. Vermeer, R. W. Risebrough, A. L. Spaans, I. M. Reynolds, Environ. Pollut., I, 217 (1974): CA 82: 93926n.

34. S. Yamatake, T. Shimamoto, S. Eguchi, K. Mori, M. Watabe, F. Myorei, H. Shimizu and T. Matsuura, Ehime Kenritsu Eise1 Kenkyusho Nempo, 37, 49 (1975): CA 87: 63739q.

35. I. A. Schipper, H. J. Herning and W. J. Promeraberger, N. D. Farm Res., 23, 4 (1964): CA 62: $1026 \mathrm{e}$.

36. D. S. Farrington and J. W. Munday, Analyst, 101, 639 (1976).

37. A. M. Robson, M. R. C. P., J. M. Kissane, N. H. Elvick and L. Pundavela, J. Pediatr., 15, 309 (1969).

38. V. Polaskova, P. Maivald, J. Koenig, B. Chundels, and J. Sobotka, Soudui Lek, 5, 27 (1969): CA 72: 2491w.

39. T. S. Carswell and H. K. Nason, Ind. Eng. Chem,, 30, 622 (1938).

40. H. E. Christensen (Ed.), Registry of Toxic Effects of Chemical Substances, p. 849 (1976).

41. J. E. Fountaine, P. B. Joshipura and P. N. Keliher, Water Res., 10, 185 (1976).

42. R. H. Pierce, C. R. Brent, H. P. Williams and S. G. Reeves, Bull. Environ. Contam. Toxicol., 18, 251 (1977).

43. R. H. Stehl, R. R. Papenfuss, R. A. Bredeweg, and R. W. Roberts, Adv. Chem. Ser., 120, 119 (1973): CA 79: 107822c.

44. T. Suzuku, J. Environ, Sci. Health, Part B, 12, 113 (1977): CA 87: 112643q.

45. G. E. Blackman, M. H. Parke and G. Garton, Arch. Biochem. Biophys, 54, 55 (1965).

46. K. Nose and K. Fukunaga, Novaku Seisan Gijutsu, $\underline{6}$, 27 (1962): CA 58: $11905 \mathrm{c}$. 
47. Beilstein's Handbuch der Organischen Chemie, 6, Ser. 11, Springer-Verlag, Berlin, '1944).

48. A. Steigmann, J. Soc. Chem, Ind, 61, 180 (1942).

49. W. Deichmann and L. J. Schafer, Ind. Eng. Chem., Anal. Ed., 14, 310 (1942).

50. S. Gottlieb and P. B. Marsh, Ind. Eng. Chem., Anal. Ed., 18, 16 (1946).

51. I. C. Mitchell, J. Assoc. Off. Anal. Chem, 4l, 781 (1958).

52. Z. Vacek, Z. Štota and J. Staněk, J. Chromatogr., 19, 572 (1965).

53. I. Suzuki and S. Kato, Eisei Shikenjo Hokoku, 81, 51 (1963): CA 62: 12981f.

54. R. Deters, Chemiker-Ztge, 86, 388 (1962): CA 57: $14229 a^{\circ}$

55. H. J. Petrowitz, Fresenius' Z. Anal. Chem., 230, 250 (1967): CA 68: 101634u.

56. G. Tadema and P. H. Batelaan, J. Chromatogr., 36, 205 (1968).

57. M. G. Zigler and W. F. Phillips, Environ, Sci. Technol., 1, 65 (1967).

58. M. Frei-Häusler, R. W. Frei and O. Hutzinger, J. Chromatogr., 84, 214 (1973).

59. J. B. LaClair, Anal. Chem., 23, 1760 (1951).

60. A. Basch and B. Hirschman, Text. Res. J., 40, 670 (1970): CA 73: 88951b.

61. J. E. Fountaine, P. B. Joshipura, P. N. Keliher and J. D. Johnson, Anal. Chem., 47, 157 (1975).

62. Z. M Teplyakova and E. K. Timbekov, Shornik Nauch. Trudov. Tashkentsk. Med. Inst., 16, 229 (1960): CA 56: 10634a.

63. W. D. Winn, U. S. Patent 3,931,001 (Jan. 1976). 
64. J. A. Barry, R. C. Vasishth and F. J. Shelton, Anal. Chem., 34,67 (1962).

65. J. Burke and I. Johnson, J.Assoc. Off. Anal. Chem., 45. 348 (1962).

66. R. H. Kolloff, I. J. Breuklander and L. B. Barkley, Anal. Chem., 35, 1651 (1963).

67. J. Kanazawa, Agr. Biol. Chem,, 27, 153 (1963).

68. R. J. Argauer, Anal. Chem., 40, 122 (1968).

69. A. Stark, J.Agr. Food Chem., 17,871 (1969).

70 A. Bevenue, J. R. Wilson, E. F. Potter, M. K. Song, H. Beckman and G. Mallett, Bull. Environ. Contam. Toxicol., 1, 257 (1966).

71. G. R. Higginbotham, J. Ress, and A. Rocke, J. Assoc. Off. Anal. Chem., 53, 673 (1970).

72. W. F. Barthel, A. Curley, C. L. Thrasher, V. A. Sedlak and $R$. Armstrong, J.Assoc. Off. Anal. Chem., 52, 294 (1969).

73. M. Cranmer and J. Freal, Life.Sci., 2, 121 (1970).

74. W. W. Kilgore and E. R. White, J. Chromatogr. Sci., 8, 166 (1970).

75. G. Yip, J. Assoc. Off. Anal. Chem, 54, 966 (1971).

76. T. M. Shafik, Bull. Environ. Contam. Toxicol,, 10, 57 (1973).

77. D. R. Buhler, M. E. Rasmusson and H. S. Nakaue, Environ. Sci. Technol., 1, 929 (1973).

78. I. J. Parr, M. G. Gee, D. G. Land, D. Robinson and R. F. Curtis, J. Sci. Food Agr, 25, 835 (1974).

79. M. G. Gee, D. G. Land and D. Robinson, J. Sci. Food Agr., 25, 829 (1974).

80. A. S. Y. Chau and J. A. Coburn. J. Assoc. Off. Anal. Chem. 57, 389 (1974).

81. E. C. Villanueva, R. W. Jennings, V. W. Burse, and R. D. Kimbrough, J. Agr. Food Chem, 23, 1089 (1975). 
82. C. D. Chriswell, R. C. Chang and J. S. Fritz, Anal. Chem., 47, 1325 (1975).

83. H. R. Buser and H. P. Bosshardt, J. Assoc. Off. Anal. Chem., 59, 562 (1976).

84. J. P. Mieure, O. Hicks, R. G. Kaley and P. R. Michael, J. Chromatogr. Sci., 15, 275 (1977).

85. H. J. Hoben, S. A. Ching, I. J. Casarett, and R. A. Young, Bull. Environ. Contam. Toxicol., 15, $78(1976)$.

86. W. Krijgsman and C. G. van de Kamp, J. Chromatogr., 131, 412 (1977).

87. H. M. Stahr, "Analytical Toxicology Methods Manual", Iowa State University Press, Ames, pp. 131-145 and 300-305 (1977).

88. R. C. Dougherty and K. Piotrowska, Proc. Natl. Acad. Sci. U. S., 23, 1777 (1976).

89. Y. Mizunoya, Bunseki Kagaku, 11, 393 (1962): CA 59: $6999 \mathrm{j}$.

90. E. A. Zemkin, V. M. Gorokhovskii, N. A. Kalinovskaya, G. L. Kogan, and V: M. Cherepnev, Zh. Nauchn. Prikl. Fotogr. Kinematogr, 20, 44 (1975): CA 83: 35612s.

91. G. C. Barker and A. W. Gardner, Z. Anal. Chem., 173, 79 (1960): CA 54: 13936g.

92. E. P. Parry and R. A. Osteryoung, Anal. Cheme, 37 , 1634 (1965).

93. G. W. Ewing, "Instrumental Methods of Chemical Analysis" McGraw-Hill, New York, pp. 298, 308309 (197.5).

94. D. E. Burge, J. Chem. Educ. 47, A81 (1970).

95. J. G. Osteryoung and R. A. Osteryoung, Am. Lab., 4. 8 (1972).

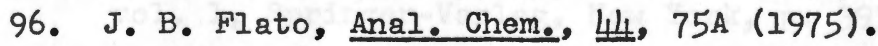

97. Princeton Applied Research Operating and Service Manual for the Model 174A Polarographic Analyzer (1976). 
98. D. T. Sawyer and J. I. Roberts, Jr., "Experimental Electrochemistry for Chemists, Wiley \& Sons, New York, pp. 75-76 (1974).

99. Ibid. p. 79.

100. R. N. Adams, "Electrochemistry at Solid Electrodes" Marcel Dekker, Inc., New York, p. 13 (1969).

101. Ibid. pp. 14-15.

102. Ibid. p. 80 .

103. G. W. Ewing, "Instrumental Methods of Chemical Analysis", McGraw-Hill, New York, P. 273 (1975).

104. Adams, "Electrochemistry at Solid Electrodes", p. 281 .

105. Ibid., pp. 26-27.

106. Ibid.

107. M. Karolczak, R. Dreiling, R. N. Adams, I. J. Felice and P. T. Kissinger, Anal. Lett., 2, 783 (1976).

108. Adams, "Electrochemistry at Solid Electrodes", pp. 143-159.

109. Ibid., p. 145.

110. Ewing, "Instrumental Methods of Chemical Analysis", pp. 312-313.

111. D. T. Sawyer and J. I. Roberts, Jr., "Experimental Electrochemistry for Chemists", p. 341 .

112. Ibid., p. 338 .

113. Ibid., p. 339.

114. Adams, "Electrochemistry at Solid Electrodes", p. 281 .

115. R. Hill, "Modern Methods of Plant Analysis", vol. 1, Springer-Verlag, New York, p. 393 (í956).

116. D. C. Kennedy, Environ, Sci. Technol., I, 138 (1973) 
117. The Aldrich Library of Infrared Spectra, 2nd Edition.

118. Sawyer and Roberts, "Experimental Electrochemistry for Chemists", p. 39.

119. Ewing, "Instrumental Methods of Chemical Analysis", p. 272 .

120. Adams, "Electrochemistry at Solid Electrodes", pp. 19-27.

121. Sawyer and Roberts, "Experimental Electrochemistry for Chemists", pp. 187-196.

122. E. Jacobsen and T. Rojahn, Anal. Chim. Acta, 61, 320 (1972).

123. K. Wedemeyer, W. Kiel and W. Evertz, German

Patent Number 1,470,929 (April 1977).

124. Bibliographic Guide for Editors \& Authors, The American Chemical Society, Washington, D. C. $(1974)$. 